\title{
Theoretical Developments in Electromagnetic Induction Geophysics with Selected Applications in the Near Surface
}

\section{Journal Article}

Author(s):

Everett, Mark E.

Publication date:

2012-01

Permanent link:

https://doi.org/10.3929/ethz-b-000042007

Rights / license:

In Copyright - Non-Commercial Use Permitted

Originally published in:

Surveys in Geophysics 33(1), https://doi.org/10.1007/s10712-011-9138-y 


\title{
Theoretical Developments in Electromagnetic Induction Geophysics with Selected Applications in the Near Surface
}

\author{
Mark E. Everett
}

Received: 5 November 2010/ Accepted: 3 June 2011/Published online: 5 July 2011

(C) Springer Science+Business Media B.V. 2011

\begin{abstract}
Near-surface applied electromagnetic geophysics is experiencing an explosive period of growth with many innovative techniques and applications presently emergent and others certain to be forthcoming. An attempt is made here to bring together and describe some of the most notable advances. This is a difficult task since papers describing electromagnetic induction methods are widely dispersed throughout the scientific literature. The traditional topics discussed herein include modeling, inversion, heterogeneity, anisotropy, target recognition, logging, and airborne electromagnetics (EM). Several new or emerging techniques are introduced including landmine detection, biogeophysics, interferometry, shallow-water electromagnetics, radiomagnetotellurics, and airborne unexploded ordnance (UXO) discrimination. Representative case histories that illustrate the range of exciting new geoscience that has been enabled by the developing techniques are presented from important application areas such as hydrogeology, contamination, UXO and landmines, soils and agriculture, archeology, and hazards and climate.
\end{abstract}

Keywords Controlled-source electromagnetics · Electrical conductivity · Near-surface geophysics

\section{Introduction}

This review describes advances made since 2007 in electromagnetic induction techniques relevant for near-surface applied geophysical investigations. I consider near-surface techniques as referring to marine, borehole, airborne, or ground-based measurements that have a penetration depth of nominally $\sim 1 \mathrm{~km}$ or less and, with a few exceptions, that are made at frequencies such that displacement currents can be neglected. This depth range includes airborne electromagnetics (AEM) and well logging, topics that are sometimes

M. E. Everett

Institut fur Geophysik, ETH Zurich, Zurich, Switzerland

M. E. Everett ( $\square)$

Department of Geology and Geophysics, Texas A\&M University, College Station, TX, USA

e-mail: everett@geo.tamu.edu 
omitted in the reviews of near-surface electromagnetics. I have avoided magnetotellurics (MT), except radiomagnetotellurics (RMT), since MT is essentially a deep exploration tool. Other related techniques such as resistivity/induced polarization (IP) or groundpenetrating radar (GPR) are not considered, except for studies in which they are integrated with electromagnetic induction techniques. Laboratory-based petrophysical studies of the low-frequency electromagnetic properties of geomaterials are also excluded. Recent overviews of near-surface electromagnetic geophysics can be found in Nobes (1996), Tezkan (1999), and Pellerin (2002).

There is a huge scientific literature on near-surface electromagnetic geophysics. Such an expansive canon precludes an exhaustive survey. Accordingly, the majority of papers reviewed herein are ones that can be found using the elementary search terms "electromagnetic induction" and "controlled-source electromagnetic(s)" in the ISI Web of Science citation index. This method of gathering information is imperfect but hopefully has led to a useful snapshot of the current state of the art in near-surface electromagnetic techniques. Many important papers surely have been missed, including those whose abstracts do not contain these search terms, or else the paper appears in a publication not represented in the citation index. I assume responsibility for omissions and apologize to the reader in advance.

The review is not tutorial in nature, so that a reader wishing to improve his or her basic understanding in a certain aspect of electromagnetic geophysics is advised to consult the appropriate paper(s) cited herein. For better or worse, the emphasis of the review is on electromagnetic techniques as opposed to the exciting and innovative geoscience that is enabled by their application. However, to illustrate the range of science that has been accomplished, I have selected representative case studies from the major application areas at the end of the review. There is also a section on new or emerging techniques. The review need not be read straight through from start to finish. Most sections are self-contained, so that a reader can jump directly to the areas of research that he/she finds most interesting. Indeed, I expect that only the most assiduous reader will parse the entire document.

The organization of the review proceeds as follows. Individual papers are assigned to exactly one of the following main categories: modeling, inversion, heterogeneity, anisotropy, target recognition, logging, airborne EM, new or emerging techniques, and selected applications. This organizational framework is also somewhat arbitrary and many of the papers stubbornly refuse to be uniquely categorized. A second apology is therefore in order in the case that I might have improperly classified a given paper. The review finishes with some closing remarks.

\section{Modeling}

Boerner (2010) has reviewed recent developments in finite difference (FD) and finite element (FE) methods for numerical solution of the 3-D electromagnetic induction forward problem. His main findings can be summarized as follows. Spatial discretization of Maxwell's equations using FD is typically accomplished using a staggered Yee grid. Material averaging schemes have been developed in FD to handle anisotropic electrical conductivity structures. A major trend in FE is the replacement of node-based elements with edge-based elements. Adaptive mesh refinement strategies have also been developed. Regardless of the spatial discretization method, efficient transient solutions have been demonstrated using DuFort-Frankel explicit and backward Euler implicit time-stepping schemes. A spectral Lanczos decomposition method (SLDM) for constructing the matrix 
exponential has also been used successfully to compute transient responses. The FE or FD linear system of equations is most often solved using iterative Krylov subspace methods of the conjugate gradient type, but direct solvers that do not require expensive preconditioning are becoming increasingly competitive. Fast multigrid solvers based on the curlcurl operator show tremendous promise. While FE and FD remain the numerical modeling workhorses, alternative modeling approaches such as finite volume (FV) and spectral-finite element (SFE) have been explored. Future advances in numerical modeling are likely to involve the implementation of parallelized codes on distributed memory systems and computing clusters.

Knizhnerman et al. (2009) have advanced the theoretical development of the SLDM method. It is already well established that SLDM allows us to solve 3-D electromagnetic induction problems simultaneously for many frequencies at the cost of a single-frequency problem. The performance of SLDM depends, however, on the specific frequencies that are chosen. The new development, based on a rational Krylov subspace approximation of the resolvent function, is to select frequencies over a bounded positive interval in a manner such that optimal convergence is obtained.

Mulder et al. (2008) evaluate transient electromagnetic responses by taking the Fourier transform of piecewise-cubic Hermite interpolated frequency-domain solutions. The computational complexity of the Fourier transform method is $\sim N_{\mathrm{f}} N^{3}$, where $N_{\mathrm{f}}$ is the number of frequencies and $N$ is the number of grid points in each spatial coordinate. This compares favorably with DuFort-Frankel and implicit time-stepping schemes that both scale as $\sim N^{4}$ and SLDM that scales as $\sim N^{4} \sqrt{\log N}$. The modeling in the frequency domain is performed using a multigrid approach, as introduced by Plessix et al. (2007). The computational grids are adapted to the source location and the frequency.

A new 3-D controlled-source electromagnetic (CSEM) FD code that employs the MUMPS direct solver is presented by Streich (2009). The MUMPS software package performs an $L D L^{T}$ factorization of the governing linear system and is parallelized for distributed memory machine architectures. Direct solvers have large memory requirements, on the order of tens of Gbytes for 3-D problems, but they offer an advantage over iterative solvers in that multiple sources can be efficiently modeled using the original factorization (see Fig. 1).

Yegorov (2009) has developed a 3-D Trefftz-type FE method. The Trefftz basis functions are the exact solutions to the governing Helmholtz equation within each discrete block of the solution domain. These exact solutions are then joined together by boundary conditions applied at the block boundaries. The resulting linear system of equations is very

(a)

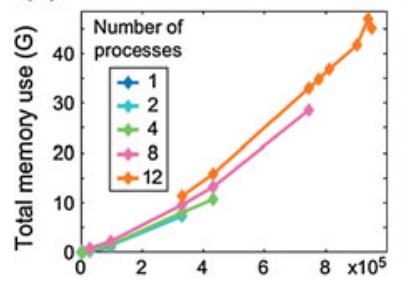

(b)

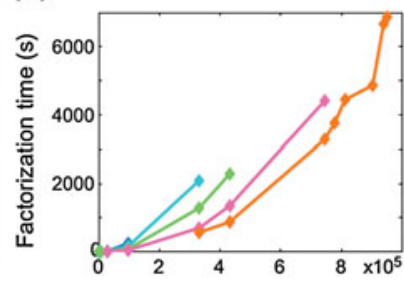

(c)

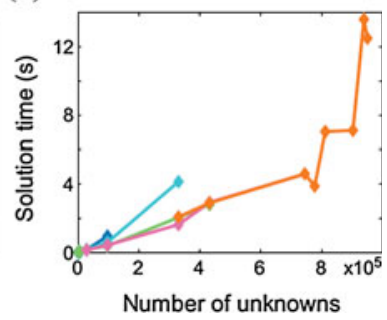

Fig. 1 Performance of the MUMPS direct solver with increasing number of unknowns in a CSEM forward modeling problem; a memory usage; b time for matrix factorization; c time for a single solution (after Streich 2009) 
sparse as only a minimal number of basis functions is required to represent the electromagnetic field. The sparse system is solved using a preconditioned Kaczmarz iterative method.

There have also been advances in integral equation (IE) modeling of 3-D electromagnetic induction problems. Singer (2008) has developed a numerical formulation of an iterative-dissipative IE that preserves the contraction properties of the continuous integral equation. Avdeev and Knizhnik (2009) describe an efficient iterative-dissipative IE algorithm whose computational load scales as $\sim N_{x} N_{y} N_{z}$, that is, linearly in the number of prisms in each of the three spatial dimensions. Previous IE algorithms of this type were found to scale as $\sim N_{x} N_{y} N_{z}^{2}$, that is, quadratic in the vertical dimension. The improvement is based on the discovery that the five main diagonals of the Green's matrix are sufficient to determine the entire matrix.

A new IE solution technique has been suggested by van den Berg et al. (2008). The scattered electric field in the frequency domain is decomposed into a first component that corresponds to scattering in the anomalous zone and a second component that represents the interaction between the anomalous zone and the background layered host. The components take the form of convolution and correlation integrals that are efficiently computed using Fourier transform techniques.

Endo et al. (2008) have developed a multigrid approach to IE quasilinear forward modeling. The term "quasilinear" is given to methods in which the anomalous electric field is assumed to take the form of a reflectivity vector multiplied by the amplitude of the background electric field. The new development is that the reflectivity vector is first computed on a coarse grid and then linearly interpolated onto a finer grid whereupon the integral equation is solved anew. Moreover, the effects of an inhomogeneous background zone can be modeled by applying the algorithm iteratively. The approach has been generalized by Endo et al. (2009) to handle multiple inhomogeneous zones.

In the conventional IE method, the unknown variable is the electric field. In regions of strong conductivity contrast up to $10^{6}$, the accuracy of the IE method tends to degrade since it is assumed that the electric field is constant over the discrete cells of the anomalous zone. At high contrast, electric fields vary rapidly in space. Zhdanov et al. (2007) have overcome this problem by formulating a new IE method in terms of the volume-integrated electric current within each cell.

With application to the offshore exploration of shallow gas hydrates in mind, Swidinsky and Edwards (2009) have formulated and solved a frequency-domain IE governing the CSEM response of an infinitely long horizontal insulating strip of finite width and vertical thickness embedded in a conductive double half-space. The integral equation emerges as a direct consequence of the physical requirement that no vertical current can flow across the strip. A transformation of the response into the time domain is achieved using the GaverStehfest inverse Laplace algorithm. A series of snapshots showing diffusion of the electric current stream function through a strip of transverse resistance $100 \Omega \mathrm{m}^{2}$ is presented in Fig. 2. In Swidinsky and Edwards (2010), the method is generalized to a resistive strip of finite length embedded in a multilayered Earth.

Metal detectors based on electromagnetic induction principles are the geophysical instruments of choice for landmine detection. Most commercial instruments feature some type of compensation circuit to account for the background soil viscous magnetic response that can overwhelm a subtle landmine signature. Druyts et al. (2009) have developed a novel Born approximation approach for calculating the effect of a background soil 

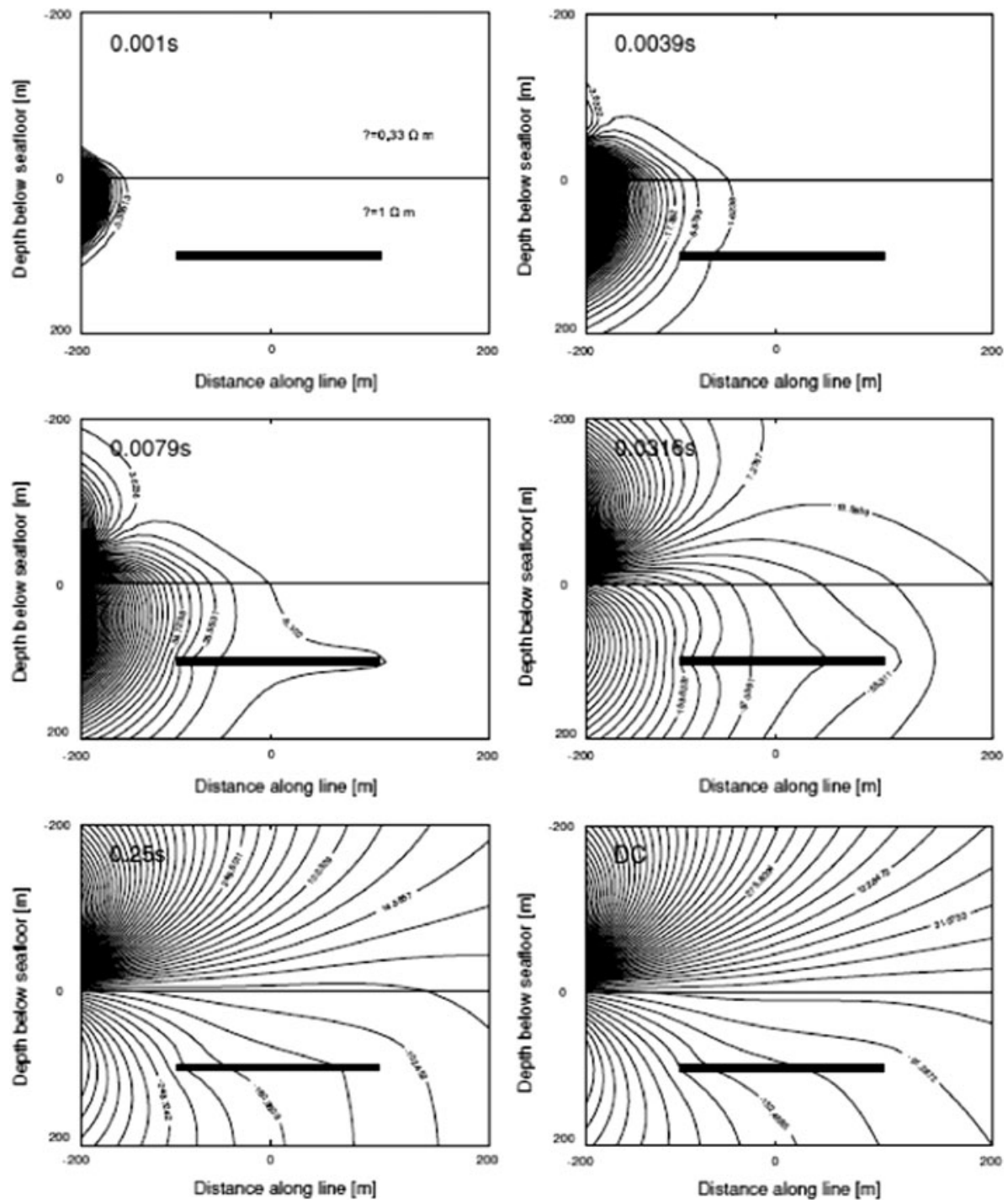

Fig. 2 2-D IE transient solutions for unit dipole excitation of a resistive strip. Contour units, $\mathrm{mA} / \mathrm{km}$ (after Swidinsky and Edwards 2009). Used with permission

half-space on the response of a generic metal detector system. The soil is presumed to be non-conductive with weak magnetic susceptibility.

\section{Inversion}

Papers published in the inversion of electromagnetic induction data during 2007-2010 can be broadly broken down into two categories: stand-alone and joint inversions with other types of geophysical data. 
To mitigate the high computational requirements for the interpretation of industry 3-D CSEM datasets, Commer and Newman (2008) have published a number of technical improvements to their existing 3-D inversion algorithm. First, the forward modeling grid and the inversion grid were made independent of each other. This required the development of a suitable material averaging scheme to transfer conductivity models between the two grids. Second, new constraints on allowable conductivity models were introduced to avoid searches of unphysical regions of model space. Finally, the code was parallelized on two levels: the tasks required to solve the linear system are split among several processors and data from different transmitter locations are sent to different processors. A significant effort was undertaken to achieve equitable load balancing among the processors.

A new 3-D inversion algorithm for large-scale CSEM datasets has been implemented by Plessix and van der Sman (2008). The forward computation uses a multigrid FV method. The computational and inversion grids are decoupled. An objective function consisting of a weighted sum of data misfit and regularization terms is minimized using a Gauss-Newton method. Two complementary types of regularization are considered. First is a blocky inversion in which the Earth is divided into a small number of regular blocks. The second is a "minimum-norm" inversion in which adherence to an a priori model, as derived, for example, from seismic interpretation, is favored.

Abubakar et al. (2008) have developed a new frequency-domain 2.5-D electromagnetic inversion based on FD forward modeling that utilizes a staggered Yee grid and a direct matrix solver. The objective function is the product, rather than the traditional weighted sum, of a data misfit term and a model regularization term. The use of a multiplicative cost function avoids the specification of a trade-off parameter between data misfit and model regularization. An interesting feature is that the forward responses are balanced such that each frequency component contributes roughly the same amount to the overall data misfit. The regularization term can be chosen to favor either smooth or blocky conductivity models. The objective function is minimized using a Gauss-Newton algorithm.

A fast thin-sheet inversion code has been presented by Singer and Fainberg (2007). The layered Earth is presumed to contain a number of thin, laterally heterogeneous zones (Fig. 3, top). A layer is thin if it is much smaller than both the skin depth and the lengthscale of lateral variations in the electromagnetic field at Earth's surface. The unknown heterogeneous conductance $S(\mathbf{r})$ of a thin conducting layer is expressed as a convolution of the data with an "admittance kernel," which can be regarded as a type of Earth filter. A similar approach is used to determine the transverse resistance $T(\mathbf{r})$ of thin resistive layer. The algorithm is fast since only convolution-type integrations are required to solve the inverse problem. An example of the reconstruction of a near-surface conductance $S(\mathbf{r})$ model for plane-wave excitation at frequency of $10 \mathrm{~Hz}$ is shown in Fig. 3, bottom panel.

Wang et al. (2008a) have developed a method for fast inversion of multicomponent induction logging (MCIL) tool responses in terms of horizontal and vertical anisotropic conductivities, $\sigma_{\mathrm{h}}$ and $\sigma_{\mathrm{v}}$, and the dip and thickness of formation beds. The forward modeling is based on a decomposition of the vertical magnetic dipole source such that the 3-D problem degenerates into a number of axially symmetric ones. A standard modematching technique is then used to solve the axisymmetric forward problems. The inversion is essentially a fixed point iteration of a non-linear function that involves the matrix of semi-analytic Frechet derivatives of the MCIL response with respect to the model parameters. To increase computational efficiency, the Frechet matrix is decomposed using singular value decomposition. 

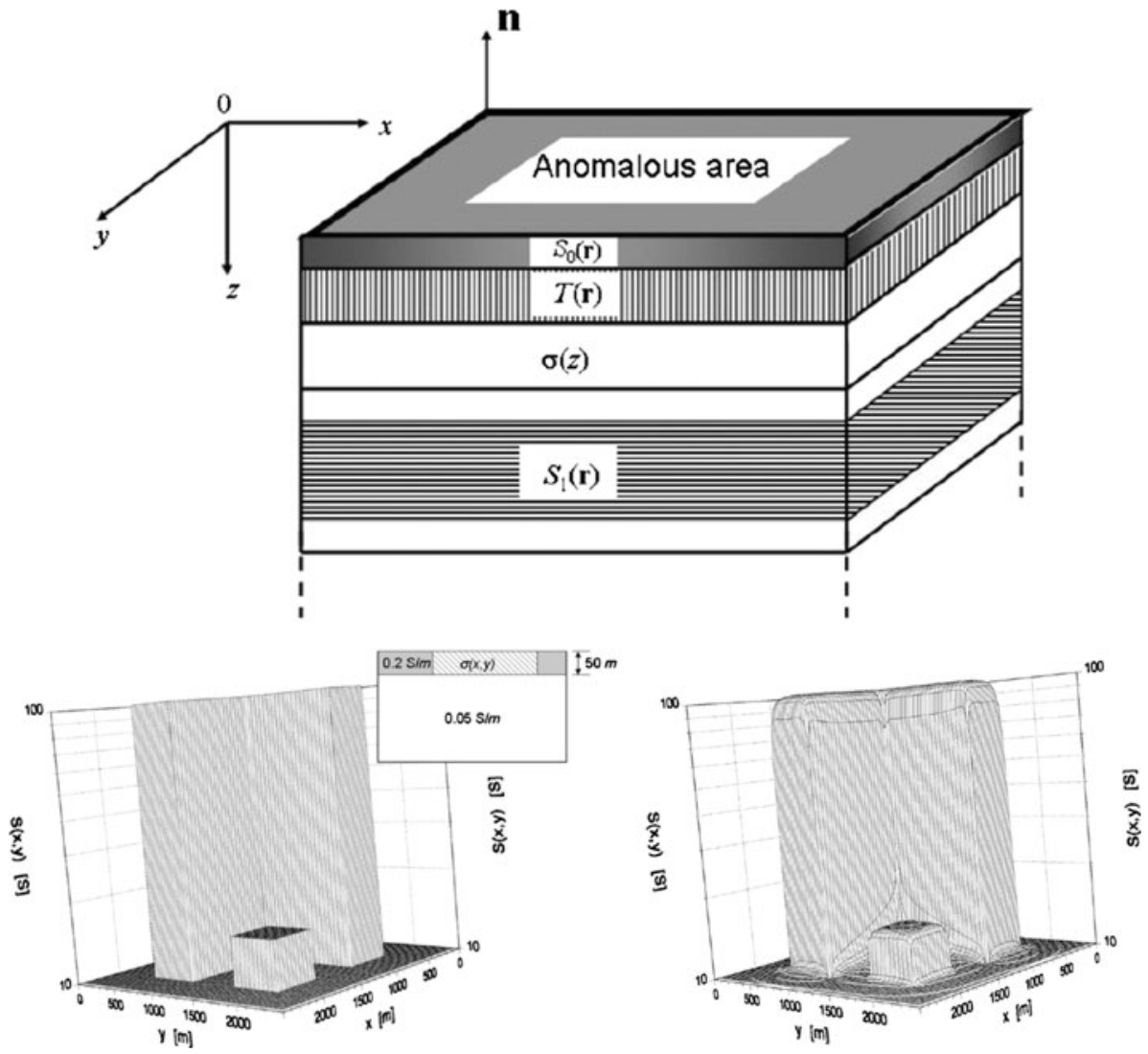

Fig. 3 (top) Thin-sheet structure showing layers of heterogeneous conductance $S(\mathbf{r})$ and transverse resistance $T(\mathbf{r})$; (bottom left) a model containing heterogeneous conductance $S(x, y)$; (bottom right) the inversion result (after Singer and Fainberg 2007). Used with permission

For mapping soil electrical conductivity as a function of depth, Monteiro Santos et al. (2010) have developed a laterally constrained 1-D inversion algorithm for horizontal coplanar (loop-loop) electromagnetic data. The forward equations, and the sensitivity functions used in the inversion, are based on analytic approximate formulas that are valid for the LIN (low induction number) regime. Adjacent 1-D inversions are constrained such that only smooth lateral variations in the conductivity-depth profiles along a survey line are allowed.

Of the joint inversion papers published during 2007-2010, the first to be mentioned is that of Hu et al. (2009). The authors combine a 2.5-D frequency-domain electromagnetic inversion, based on FD forward modeling, with a 2-D seismic inversion. The GaussNewton method is used to optimize the objective function that is characterized by a multiplicative regularization term and frequency balancing. The algorithm simultaneously finds electrical conductivity and seismic P-wave velocity models that have similar piecewise-constant structure. This is accomplished by means of a "cross-gradient" term in the objective function that is minimal when structural discontinuities in the electrical and seismic structure are aligned and maximal when they are mutually perpendicular. The 
justification for enforcing structural similarity is that both physical properties are related to porosity.

Candansayar and Tezkan (2008) have developed a 2-D joint inversion of radiomagnetotelluric (RMT) and DC resistivity data using a regularized least-squares approach. The FD method was used for both forward solvers. Electrical conductivity is the common physical property of the Earth probed by the two geophysical techniques. Hence, the RMT and DC data can be treated equivalently and were placed together into a single data misfit term of the objective function.

An example of buried target parameter estimation is given by Stalnaker and Miller (2007). The forward problem is based on the analytic expression for the electromagnetic response of a polarizable magnetic dipole. The authors use a combination of LevenburgMarquardt (LM) and particle swarm optimization (PSO) to determine optimal dipole parameters. LM is a gradient-based descent method that performs best in the vicinity of a local minimum of the objective function. PSO is an evolutionary global optimization technique that mimics the collective problem-solving capability emergent in large natural groups such as flocks of birds or swarms of insects. In this application, a few PSO iterations were used to find a good starting model for the LM algorithm.

Monteiro Santos and El-Kaliouby (2010) have presented 1-D joint inversions of DC resistivity and time-domain electromagnetic (TDEM) data based on semi-analytic layered forward modeling. The two geophysical methods are complementary since DC better resolves resistive layers, whereas TDEM better resolves conductive layers. Local and global techniques for the optimization of a misfit function are compared in this paper. The local method, based on weighted least-squares, and the two global methods, simulated annealing (SA) and PSO, produce similar conductivity models, although least-squares is faster than the global methods, while SA is very slow. The global methods are better suited to study model equivalence. Bala and Pieta (2010) have performed a similar 1-D joint inversion study based on Monte Carlo global optimization. It was shown that DC resistivity and loop-loop electromagnetic data interpreted together can also help overcome model ambiguities.

\section{Heterogeneity}

A common approach in electromagnetic geophysics for contending with near-surface heterogeneity is to regard electrical conductivity as a spatially random variable. As shown below, many of the recent advances in treating electromagnetic heterogeneity have been made by soil scientists and hydrologists.

Abdu et al. (2008) have mapped apparent electrical conductivity $\sigma_{\mathrm{a}}$ variations using a loop-loop electromagnetic instrument across a large ( $~ 38$ ha) watershed. A spatial statistical analysis was undertaken to evaluate the pattern of subsurface soil moisture and to explore its possible impact on the local ecohydrology. Kriging was first employed to provide a spatially continuous map of the discrete $\sigma_{\mathrm{a}}$ measurements. The uncertainty of the $\sigma_{\mathrm{a}}$ map was then estimated using a sequential Gaussian simulation technique. In general, $\sigma_{\mathrm{a}}$ values systematically decreased with distance away from known and suspected subsurface fluid flow paths.

A problem of great concern in irrigated agricultural areas is soil salinization. The potential for salinization depends on the soil properties and local hydrogeology, which in turn is correlated with the underlying stratigraphy. Triantafilis and Buchanan (2009) have performed a cluster analysis of kriged loop-loop $\sigma_{\mathrm{a}}$ data acquired across a watershed by 
(a)

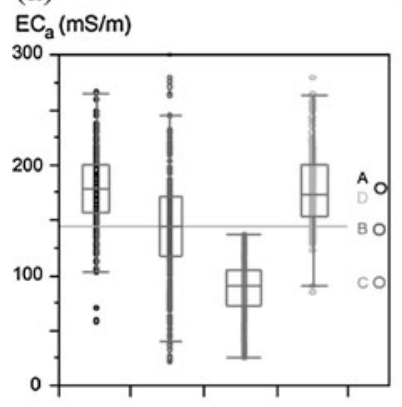

(b)

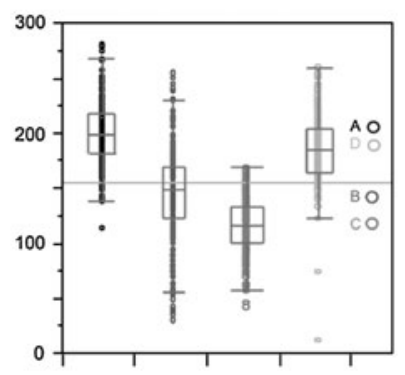

(c)

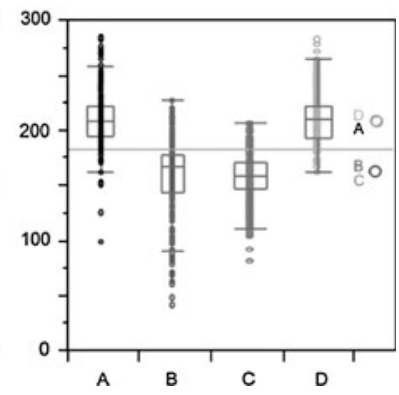

Fig. 4 Distribution of EM34 apparent conductivity readings within each of the $k=4$ classified stratigraphic units A-D: a 10-m; b 20-m; c 40-m intercoil spacing (after Triantafilis and Buchanan 2009)

means of a fuzzy $k$-means algorithm. They find that the $\sigma_{\mathrm{a}}$ measurements group statistically into several classes, with each class being interpreted as a different stratigraphic unit (Fig. 4). In this way, loop-loop electromagnetic data were used to partition a watershed into its constituent stratigraphic units.

A spatially continuous $\sigma_{\mathrm{a}}$ map is often required for a complete statistical analysis of soil and hydrological processes at the landscape or watershed scale. However, near-surface electrical conductivity can exhibit sharp discontinuities at boundaries between areas of different soil types or land management practices. Brenning et al. (2008) have developed a geostatistical regularization method for smoothing $\sigma_{\mathrm{a}}$ data across such discontinuities. The method generates a large-scale continuous $\sigma_{\mathrm{a}}$ map, ideal for studying watershed hydrology, while preserving the local statistical properties of the $\sigma_{\mathrm{a}}$ measurements within each of the different areas. A similar study has been performed by Weller et al. (2007).

Weiss and Everett (2007) have proposed a novel approach for using loop-loop electromagnetic data to characterize geomaterials that exhibit length-scale-dependent heterogeneity. Generalized Maxwell equations involving a fractional time derivative are introduced to simulate the anomalous diffusion of electromagnetic eddy currents into such media. The algorithm has its physical basis in terms of a random walk of charge carriers within a confined geometry. The theory was tested on transient loop-loop data acquired over a central Texas river floodplain (Fig. 5). Everett (2009) has developed an analytic solution to the fractional Maxwell equations for modeling anomalous electromagnetic diffusion into a rough half-space. Decker and Everett (2009) have extended the calculations to a rough multilayered Earth.

\section{Anisotropy}

The electrical conductivity of the near-surface zone is oftentimes anisotropic, which can greatly complicate electromagnetic data interpretation. The effects of anisotropy have been explicitly treated in a number of papers published between 2007 and 2010. Many of the advances in electrical anisotropy have come from the petroleum geophysics community.

Newman et al. (2010) have presented an algorithm for smooth 3-D inversion of marine CSEM data in the presence of electrical anisotropy (Fig. 6). The conductivity tensor is uniaxial, with vertical axis of anisotropy, such that the Earth is horizontally isotropic. The horizontal and vertical conductivities, $\sigma_{\mathrm{h}}$ and $\sigma_{\mathrm{v}}$, respectively, are assumed to be constant 
Fig. 5 Eddy current diffusion time as a function of squared source-receiver separation over a central Texas river floodplain. The anomalous diffusion hypothesis predicts the observed linear relationship (after Weiss and Everett 2007)

Fig. 6 Smooth inversion of marine CSEM data from Troll Field in terms of an isotropic (top panel) and a unixial (bottom two panels) electrical resistivity tensor (after Newman et al. 2010)
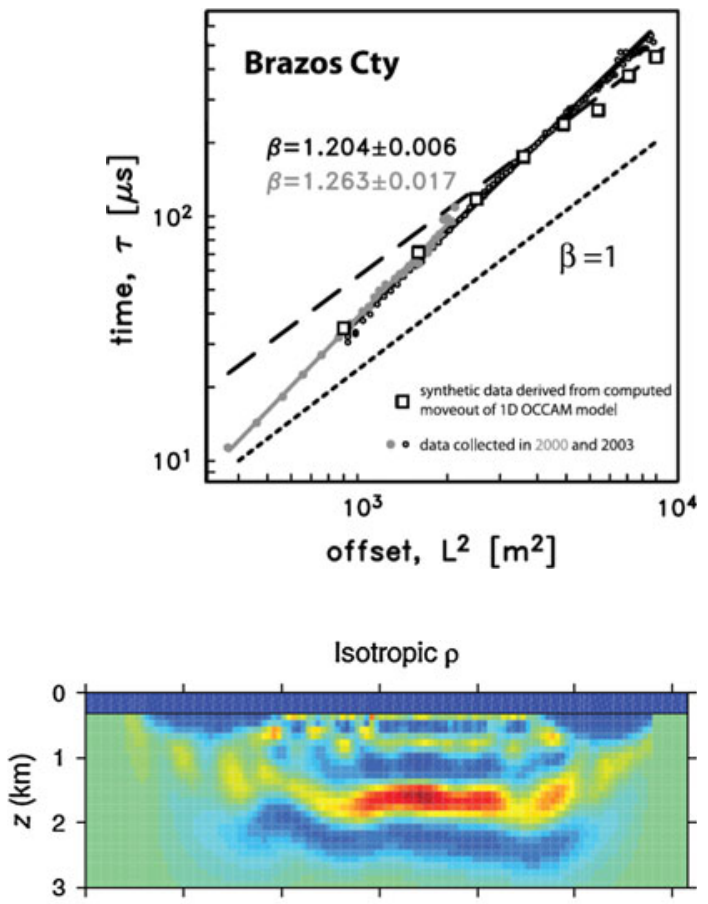

Anisotropic $\rho$ (horizontal)

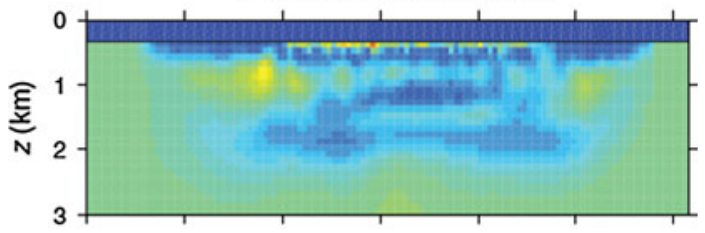

Anisotropic $\rho$ (vertical)

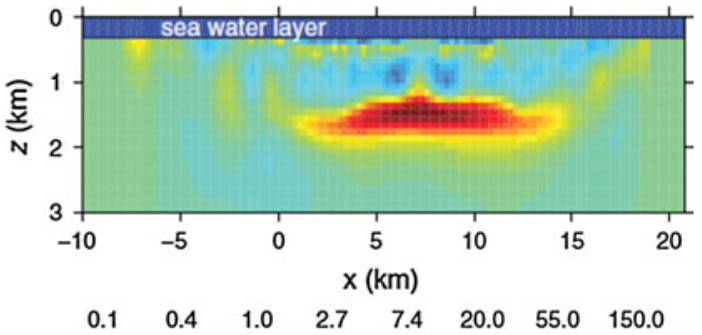

$\rho(\Omega-m)$

within each cell of the modeling grid. Smoothing of the two conductivities is performed independently. The condition $\sigma_{\mathrm{h}} \geq \sigma_{\mathrm{v}}$, which is appropriate for fine-scale sedimentary interbedding, is not required to be explicitly enforced. It is found that broadside data respond mainly to $\sigma_{\mathrm{h}}$, while inline data are most sensitive to $\sigma_{\mathrm{v}}$. While this example is not a near-surface application stricto senso, it is included here since it is a major advance of the state of the art in 3-D anisotropy inversion. 
Sun and Nie (2008) have introduced a new 3-D FE forward code for modeling multicomponent induction logging (MCIL) responses in deviated wells in the presence of electrical anisotropy. The formation conductivity tensor is uniaxial with the axis of anisotropy perpendicular to bedding planes. A special feature of their approach is the use of hierarchical vector finite elements that permit the electromagnetic field to be modeled with higher-order basis functions at locations where it varies rapidly such as material interfaces or close to the transmitter.

Other logging papers published during 2007-2010 that have considered electrical anisotropy include Wang et al. (2008b) and Zhong et al. (2008), both of whom have generated semi-analytic 1-D solutions for MCIL tool responses in stratified formations characterized by uniaxial electrical anisotropy.

Epov et al. (2010) have used analytic formulas to calculate fixed-offset loop-loop frequency-domain and time-domain electromagnetic responses in the presence of a uniform anisotropic half-space. The principal axes of the uniaxial conductivity tensor intersect the horizontal plane obliquely. To recover the anisotropy from field measurements, frequency-domain loop-loop data should be acquired over a range of receiver azimuths (Fig. 7). Moreover, the early-time transient embeds information about the anisotropy in its zero-crossing time as the response switches from positive to negative. The late-time transient response however is not diagnostic of the anisotropy.

General expressions for the electromagnetic fields in a stratified medium containing arbitrary anisotropy have been derived using a matrix propagator approach by Løseth and Ursin (2007). All three electromagnetic properties, namely electrical conductivity $\sigma$, permittivity $\varepsilon$, and magnetic permeability $\mu$, are assumed to be piecewise-constant dyadic tensors. The method is based on solving a system of ordinary differential equations for the field components following their 2-D Fourier transformation in the horizontal directions. Formulas are provided for fields generated by horizontal and vertical electric dipole sources and horizontal and vertical magnetic dipole sources.

\section{Target Recognition}

In this category, I consider papers from 2007 to 2010 that describe new electromagnetic induction techniques for probing buried compact targets such as metallic spheres and other artifacts of regular geometry that can be described by a small number of parameters.
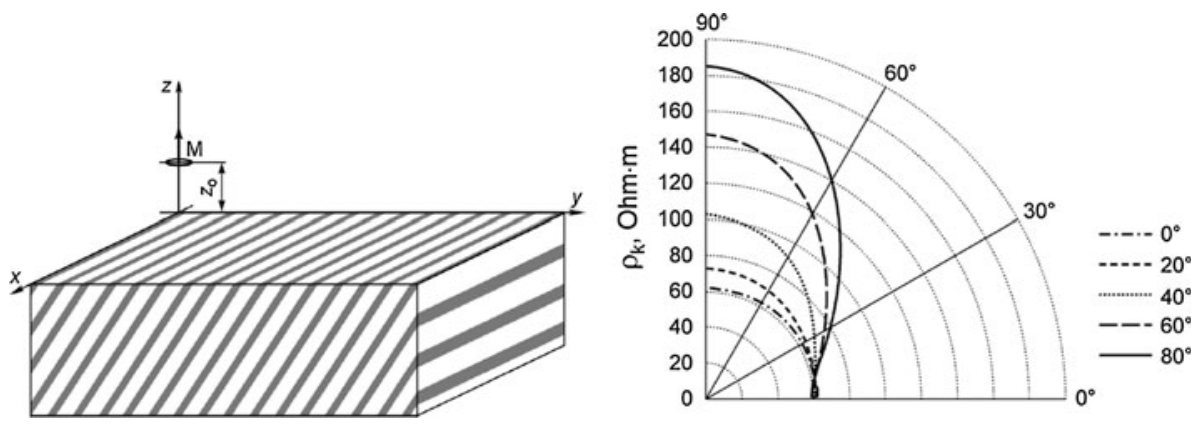

Fig. 7 (left) Loop excitation of a uniform half-space characterized by an inclined, uniaxial conductivity tensor; (right) apparent resistivity at $1 \mathrm{kHz}$ as a function of receiver azimuth, for different inclinations of electrical anisotropy (after Epov et al. 2010). Used with permission 
Topics of interest here range from forward modeling to target parameter estimation. Most of the advances in this area have come from the unexploded ordnance (UXO) community.

Oftentimes in near-surface geophysics, it is possible to recognize buried artifacts directly from the measured data. For example, an underground utility can appear as a diffraction hyperbola in a GPR section or a buried steel pipeline can appear as a distinctive linear total-field anomaly in a magnetics dataset. Kadioglu and Daniels (2008) have described a new method for visualizing buried artifacts from combined displays of groundpenetrating radar GPR and transient electromagnetic data. The visualization, which can be optimized using judicious choices of colors, opacity, filters, and other graphics processing tools, in this case enables the discrimination of subsurface metallic from non-metallic objects. The method is applied to an investigation into the buried remnants of former industrial activity at a brownfield site.

Several papers have reported progress in forward modeling of buried, highly conductive bodies. Asten and Duncan (2007) have developed a fast approximate forward algorithm for determining the electromagnetic response of a permeable, highly conductive target. The surface of the body is decomposed into a number of rectangular facets, each of which is modeled as a set of concentric wire loops that is inductively coupled to the transmitter and to the other facets. Some important effects of permeability such as enhanced flux-gathering, demagnetization, and non-linearity are incorporated heuristically into the modeling algorithm.

Chen et al. (2007) have represented the electromagnetic excitation and response of a highly conductive object as linear superpositions of prolate spheroidal basis functions. The response can be regarded as a set of scattering coefficients corresponding to a given spheroidal mode of excitation. The scattering coefficients for a given object and excitation mode are obtained by regularized least-squares fitting to electromagnetic measurements. It is found that only a few scattering coefficients are required to characterize the electromagnetic response of most objects, including bodies of revolution (BORs) such as an ellipsoid and non-BORs such as a rectangular plate. A comparison of theory and measurement for a $60-\mathrm{mm}$ mortar target is shown in Fig. 8. In a related study, Zhang et al. (2008) have applied supervised machine learning algorithms to classify targets according to size based on their spheroidal mode responses.

Bréard et al. (2009) have developed a method for computing the loop-loop forward electromagnetic response of a conductive ellipsoid buried in a conductive half-space. The
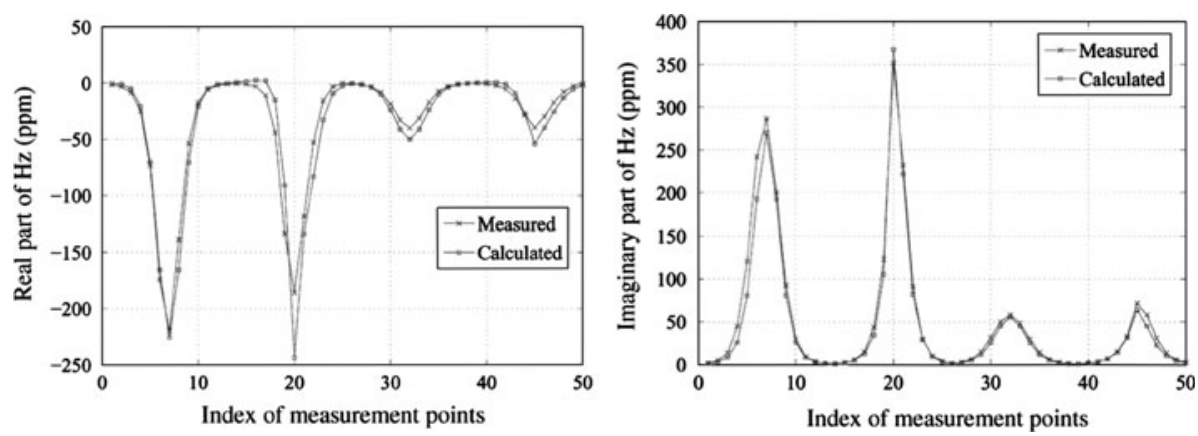

Fig. 8 Simulated and measured loop-loop EM responses over a buried 60-mm mortar. The first (second) 25 measurement points in each plot refer to the sensor at height $0.165(0.265) \mathrm{m}$ above the target; (left) real; (right) imaginary magnetic response (after Chen et al. 2007) 
ellipsoid is of small size compared with the skin depth in the host medium, and the conductivity contrast between the ellipsoid and the host is low to moderate. Under these conditions, the ellipsoid can be regarded as a polarizable electric dipole. The secondary electromagnetic field is simply that generated by the dipole situated in free space, multiplied by the product of the ellipsoid/host conductivity contrast and a depolarization tensor that depends on the ellipsoid semiaxis lengths. Multiple ellipsoids are modeled using a variant of Lax-Foldy theory in which the field incident on the $n$-th ellipsoid is equal to the sum of the primary half-space field plus the sum of the secondary fields from the other $n-1$ ellipsoids. In a closely related paper, Bréard et al. (2008) have applied an evolutionary algorithm, a type of global optimization method, for the retrieval of buried ellipsoid parameters from loop-loop impedance measurements.

The electromagnetic characterization of buried conductive targets is difficult in ironbearing magnetic soil environments. In such cases, the spatially varying background geological noise degrades target parameter estimations. In particular, the electromagnetic response is affected by factors that alter the relative position of the sensor to the background geology, such as along-track variations in topography and sensor orientation. Pasion et al. (2008) have presented a unique method for coestimation of target parameters with the long-wavelength geological signal, based on an approximate analytical formula for the loop response of a permeable half-space. The magnetic soil is assumed to be nonconductive but possesses viscous remanent magnetization (VRM).

Smith et al. (2007) have developed a method for accurate target parameter estimation that is based on the concept of null coupling between a transmitter and a receiver. A nullcoupled receiver records only the secondary field from the target of interest, and it is insensitive to the much larger primary field from the transmitter. Since multiple transmitters are employed in the latest generation of sensors, it is often impossible to deploy a traditional single null-coupled receiver. The authors have discovered, however, that the difference in responses from receivers that are placed in appropriate symmetric positions with respect to the multiple transmitters can generate a null signal. Furthermore, the inversion of the null signal in terms of target parameters is robust with respect to positioning errors.

In the time domain, it is well known that the electromagnetic response from a buried conductive targets can be expressed as a series of damped exponentials, in which the time constants of the exponentials are known as relaxation times. The distribution of relaxation times encodes information about the target size, shape, location, composition, and other attributes. Equivalently in the frequency domain, a spectrum of relaxation frequencies can be defined. Wei et al. (2010) have formulated a constrained linear optimization technique to extract the relaxation frequencies from frequency-domain electromagnetic measurements.

An innovative technique for target parameter estimation has been published by Shubitidze et al. (2008). The method assumes that the electromagnetic response of the target, in the form of the magnetic field $\mathbf{H}$, has been measured everywhere on some horizontal plane above the target. A set of equivalent magnetic dipoles is then found that can explain the magnetic field data. These dipoles are restricted to lie in a horizontal plane above the target, but below the plane of measurements. Once the equivalent dipoles are found, the magnetic vector $\mathbf{A}$ and electric scalar potential $\psi$ they generate are computed everywhere on the measurement plane. Knowledge of the set $(\mathbf{H}, \mathbf{A}$, and $\psi)$ everywhere on the measurement plane is sufficient to retrieve the target's location and magnetic polarizability tensor. 
Song et al. (2008a) have developed a method for determining the location of a buried target from data recorded by an array of electromagnetic induction sensors. Their method is similar in principle to the beamforming concept used for source localization in sonar and radar array processing. The major assumption is that the target can be represented as a polarizable point dipole. In this case, the source power, defined as the sum of squares of the elements of the dipole polarizability tensor, presumably emerges from a single point beneath the sensor array. The source localization procedure can then be cast as an optimization problem: find the point of source activity that best explains the observed measurement power across the sensor array. The method is also capable of distinguishing multiple closely spaced targets that combine to generate a single electromagnetic anomaly.

Tarokh and Miller (2007) have addressed the target parameter estimation problem in the presence of sensor positioning errors. The forward problem is based on a polarizable point dipole. The authors have formulated a min-max optimization scheme in which the optimal target parameters are those that minimize the maximum misfit to a set of electromagnetic induction data. The maximum misfit, for any candidate set of target parameters, is obtained by generating a sample of likely sensor locations and comparing the corresponding misfits.

Other papers from 2007 to 2010 that have examined electromagnetic induction in buried compact targets include McKenna and McKenna (2010), who have built upon previously known analytical solutions to explore loop-loop triaxial (three-component receiver) electromagnetic responses of buried linear conductors that are indicative of civil infrastructure, such as a pipeline or the electrical cabling often found inside a tunnel. Song et al. (2008b) have extended the spheroidal excitation approach (SEA) of forward modeling into the time domain and have computed transient electromagnetic responses from buried compact targets. Walker et al. (2007) have studied various experimental factors that can degrade the quality of transient electromagnetic datasets used for buried target discrimination.

\section{Logging}

There is strong overlap between this section of the review and the modeling section mainly because it is not possible in my organizational framework to uniquely classify logging papers that contain new modeling methodologies. The reader interested in advances in logging is therefore advised to read also the modeling section.

Davydycheva (2010) has reviewed developments over the past decade in the logging of petroleum wells using the principles of electromagnetic induction combined, in some cases, with electromagnetic wave propagation. Her main findings relative to new instruments and data processing techniques can be summarized as follows. A number of tools have been introduced for both wireline and logging-while-drilling (LWD) scenarios. The new instrumentation has focused on full tensor measurement using triaxial transmitters and triaxial receivers, thus providing new capabilities for detecting azimuthal heterogeneities and analyzing formation anisotropy. Newly developed data processing techniques such as multifrequency focusing (MFF) correct for distortions found in triaxial wireline data due to the borehole, the invasion zone, and tool eccentricity. Symmetrization and rotation of tensor measurements allows the separation of borehole effects from those of dipping beds and formation anisotropy. The latest generation of LWD propagation resistivity tools features antennas that are tilted with respect to the borehole axis. Such configurations take advantage of the tool rotation to provide directional measurements for improved geosteering. 
An overview of advanced strategies for hydrocarbon reservoir characterization based on LWD electromagnetic data has been provided by Omeragic et al. (2010). A forward modeling toolkit consisting of parallelized 2-D and 2.5-D FE and FD codes is described. The forward codes are utilized for a number of purposes including experimental design and sensitivity studies, geosteering, and post-acquisition data analysis. The authors provide case histories showing typical workflows for a faulted and a deepwater turbidite reservoir.

A wide range of numerical modeling approaches has appeared in the logging literature. For example, a spectral method for computing triaxial induction responses in a medium with biaxial anisotropy has been developed by Yuan et al. (2010). A thinly laminated sand-shale sequence cross-cut by fractures generates biaxial anisotropy. The governing Maxwell equations are Fourier transformed in all three spatial directions, and the resulting spectral-domain equations are solved algebraically. For the inverse Fourier transform, standard quadrature routines are used to integrate over the horizontal wavenumbers, while a contour integration is required for the more challenging vertical wavenumber.

Davydycheva et al. (2009) have described a 3-D FD code in cylindrical coordinates based on the SLDM formalism. The code uses a staggered Yee grid and material averaging to handle high conductivity contrasts. Formation anisotropy is described by a uniaxial conductivity tensor with its axis perpendicular to dipping bed interfaces. The code is applied to optimize the design of a triaxial array induction tool to minimize borehole and tool eccentricity effects.

For modeling wireline and LWD responses in deviated wells, Pardo et al. (2008) have developed new 3-D forward modeling capabilities building on a previous 2-D FE algorithm for DC resistivity logging. In the new method, a quasi-cylindrical coordinate system $\left(\zeta_{1}, \zeta_{2}, \zeta_{3}\right)$ is introduced (Fig. 9, top left) in which coordinate $\zeta_{2}$ is periodic over the interval $[0,2 \pi)$. This facilitates a Fourier mode expansion in terms of $\zeta_{2}$. A finite element discretization is then constructed in terms of the other two variables $\left(\zeta_{1}\right.$, $\zeta_{3}$ ). In this way, the 3-D simulation code reduces to a series of 2-D forward problems. The method is fast compared with other 3-D codes since only a few Fourier modes are generally required to solve practical problems. An example of a forward simulation based on the modeled wireline logging tool in Fig. 9, top right is shown in Fig. 9, bottom panel. A similar forward modeling approach is used by Wang et al. (2009) who solve 2-D problems by a semi-analytic method and address uniaxial formation anisotropy.

Epov et al. (2007) have developed a 3-D forward modeling code for high-resolution induction logging (HFIL) applications. An FE formulation in terms of the electric $\mathbf{E}$ field is adopted along with hexahedral edge-based elements and a multigrid linear solver. The code is applied to predict the HFIL response of a thin conductive layer containing clays or conductive drilling muds.

Lee and Teixeira (2007) have implemented an explicit finite-difference time-domain (FDTD) formulation on a staggered grid. A leapfrog update scheme is used to handle the time derivative in governing difference equations. The code is applied to simulate LWD responses in cylindrical media characterized by a fully anisotropic conductivity tensor and dipping bed interfaces. Hue and Teixeira (2007) have used the numerical modematching method to evaluate the induction response of tilted loop antennas in cylindrically stratified formations with uniaxial anisotropy. For solving similar problems, Novo et al. (2007) have developed a new FV technique based on a vector-scalar $(\mathbf{A}, \varphi)$ potential formulation. 

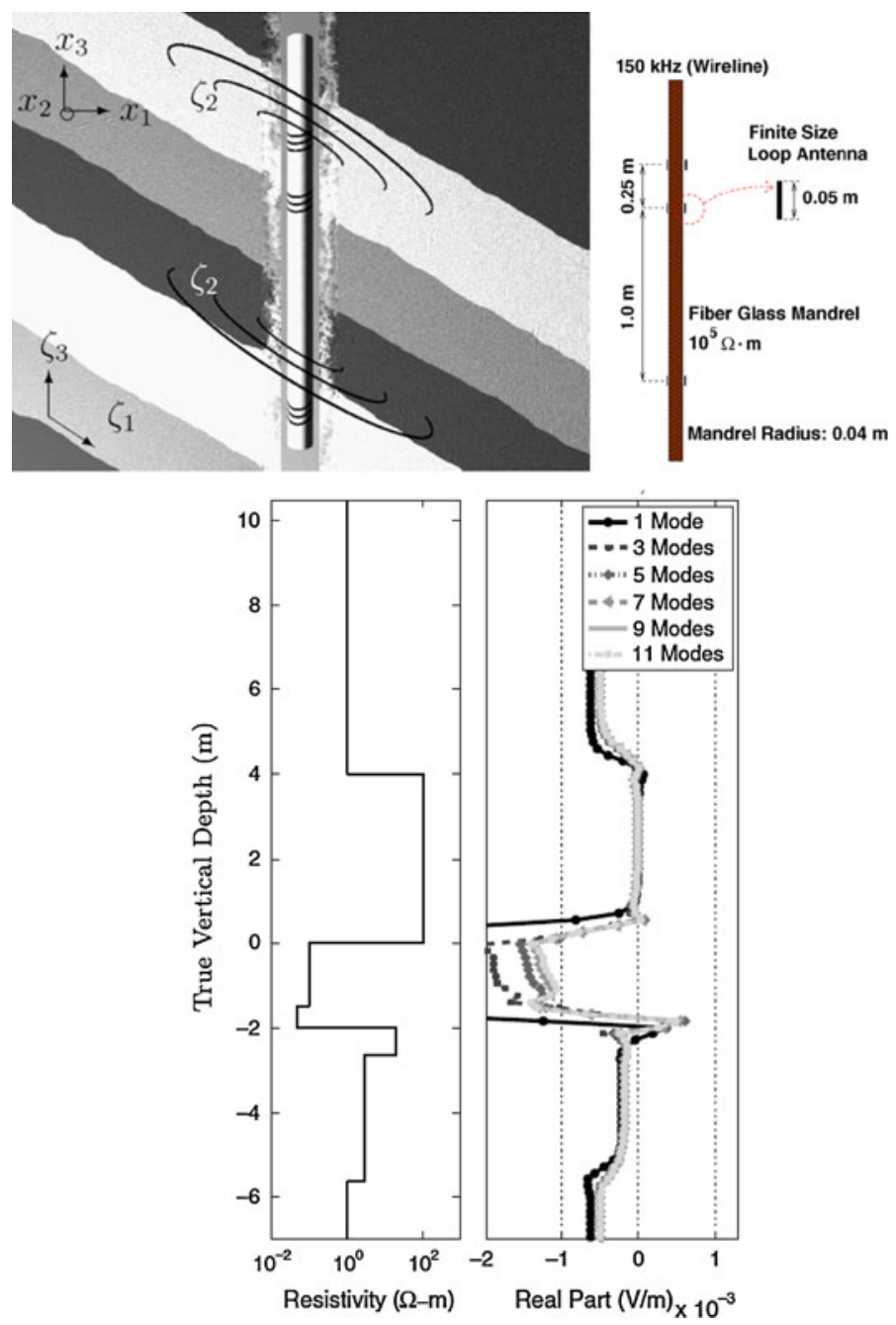

Fig. 9 (top left) Quasi-cylindrical coordinate system used for 3-D EM logging simulations; (top right) modeled wireline logging tool containing one TX and two RX coils; (bottom left) a layered resistivity model; (bottom right) wireline logging-tool model response, defined as the difference in real component of the electric field measured by the two RX's, for different numbers of superimposed Fourier modes; well deviation is $60^{\circ}$ (after Pardo et al. 2008). Used with permission

\section{Airborne Electromagnetics}

A significant number of advances in AEM techniques have occurred within the 2007-2010 time frame. Herein, I review a small sample of these contributions.

An inversion of AEM data for 3-D geological structure is highly time-consuming since a separate forward problem and sensitivity evaluation must be calculated for each transmitter position. Cox et al. (2010) have developed a fast method for inverting 3-D AEM data. The authors recognize that the AEM footprint, defined as the area of ground surface beneath the airborne measurement platform that contributes to the observed AEM signal, is 


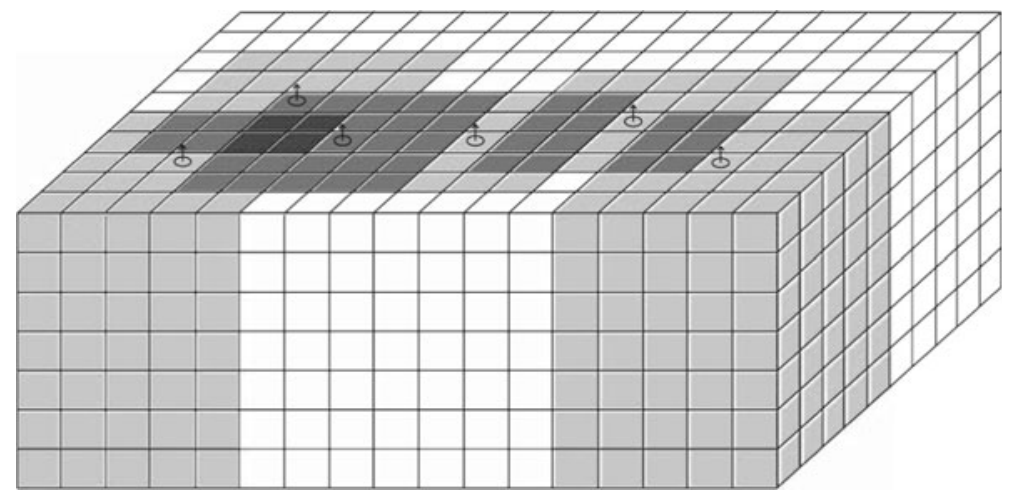

Fig. 10 The footprint (shaded regions show overlapping footprints) of an AEM exploration system is much smaller than the forward modeling domain (after Wilson et al. 2010)

generally much smaller than the overall size of the AEM survey (Fig. 10). In that case, the size of the forward modeling domain can be truncated to the size of the AEM footprint, thus greatly reducing the cost of forward solutions. The AEM inversion is based on a 3D IE forward code and a regularized conjugate gradient algorithm for minimizing the objective function. Further elaboration of this method has been provided by Wilson et al. (2010).

A real-time conductivity-depth imaging algorithm for helicopter time-domain AEM data has been presented by Huang and Rudd (2008). The AEM system consists of a large transmitter loop with smaller horizontal and vertical receiver loops placed in the center. The time constants and amplitudes of the exponentially decaying transient signals acquired along a flight track are converted into estimates of apparent conductivity and effective depths. In this way, a laterally contiguous suite of conductivity-depth profiles is constructed that can then be assembled into 2-D sections and 3-D volumes depending on the survey flight line geometry. The imaging algorithm is based on the system response to a pseudolayer half-space model in which a half-space model is overlain by a perfectly resistive layer that accounts for errors in the system altitude determination caused by factors such as altimeter errors and the occurrence of forest canopy.

Vallée and Smith (2009) have performed a laterally constrained 1-D inversion of timedomain AEM data for hydrogeological applications. The lateral constraint restricts alongtrack model roughness such that only slowly varying 2-D conductivity models are permissible. The forward problem and constraints are combined into a linearized system of equations for unknown model parameter perturbations. These equations are solved by an iterative least-squares singular value decomposition (SVD) method, otherwise called a Jupp-Vozoff damped eigenparameter inversion. The cultural noise ${ }^{1}$ found in the dataset proved difficult to suppress.

A very similar approach has been taken by Viezzoli et al. (2008) to construct threedimensional, spatially constrained 1-D inversions of time-domain AEM data. In this method, a Delaunay triangulation of the modeling domain (Fig. 11) is used to identify neighboring model parameters. The Delaunay algorithm works well with irregularly

\footnotetext{
1 The term "cultural noise" is well-known in electromagnetic geophysics to denote a buried and/or aboveground man-made metallic object such as a pipeline, steel fence, or storage tank located within or in the vicnity of an electromagnetic survey and whose unwanted response distorts the wanted geological signal.
} 
(a)

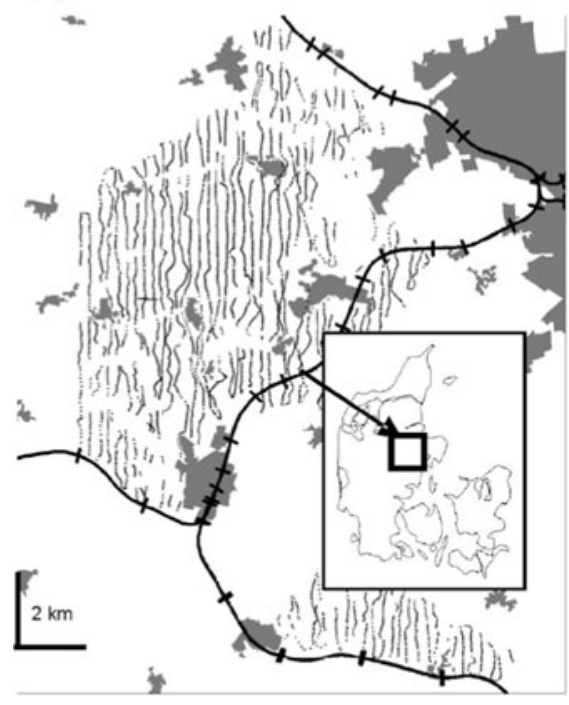

(b)

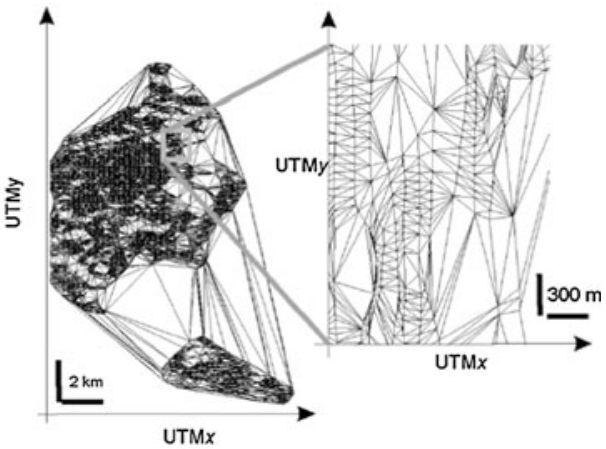

Fig. 11 a SkyTEM flight lines from an AEM survey in Denmark; b Delaunay triangulation of individual data points (after Viezzoli et al. 2008)

spaced data points. It is found that enforcement of model smoothness constraints across adjacent flight lines helps to reduce the flightline-parallel striping that often degrades AEM datasets. The linearized system on which the inversion is based is solved using a Choleski decomposition with back substitution.

An innovative method for calibrating AEM datasets has been devised by Yin and Hodges (2009). In their method, a wire loop is laid out on the ground surface and AEM data are acquired over it. The resistance and inductance of the wire loop can be changed to explore variations in the AEM system response. The authors examine the part of the signal corresponding to the mutual inductance between the wire loop and the underlying Earth. This is done by calculating the response of a uniform half-space to energization by the eddy current in the wire loop that is caused by the primary disturbance in the airborne transmitter. It is found that the time taken for the loop-earth signal to dominate the overall response increases with the underlying resistivity of the ground.

Fraser and Hodges (2007) compare datasets acquired with a horizontal coplanar looploop system that is first flown at helicopter altitude $h$ and then towed along the ground. The in-phase electromagnetic response in the inductive limit is large and positive for the flown system and large and negative for the towed system and vanishes at $h \sim 0.35 s$, where $s$ is the intercoil spacing. Commensurate with expectations, the penetration depth of the flown system is larger, while the spatial resolution of the towed system is greater.

\section{New or Emerging Techniques}

There have been several innovative applications of near-surface electromagnetic geophysics over the time span 2007-2010, many of which hold promise for future breakthroughs in our interpretation capabilities or could enable new and exciting geoscience 
discoveries, in different application areas. I have selected a few for inclusion in this section.

In many applications of near-surface geophysics pertaining to environmental site characterization, inferences based on electromagnetic induction data alone are typically not sufficiently persuasive to satisfy significant numbers of stakeholders. Uncertainty is often reduced when electromagnetic data are properly combined with other types of geophysical data. To further explore this concept, consider the problem of landmine detection. This is an emerging subdiscipline of geophysics that requires exacting measurements and meticulous data processing and interpretation due to the huge cost of false alarms. Landmine detection systems under development typically consist of multisensor configurations including GPR, electromagnetic induction, and supporting instrumentation such as infrared cameras. It is critical that the different components of the multisensor system work synergistically to provide the best possible decision on whether or not a mine is present. To this end, Frigui et al. (2010) have presented a new multisensor fusion algorithm, based on the principles of statistical classification, that optimally combines GPR and electromagnetic induction information. The authors have demonstrated that the fusion algorithm outperforms either detector working alone or both detectors working with equal weight (Fig. 12).

Biogeophysics is another emergent subdiscipline that seeks to understand the geophysical signatures of subsurface microbial activity and the manner in which microorganisms affect geological processes. Recently, Atekwana and Atekwana (2010) have reviewed advances in applications of the electrical and electromagnetic geophysical techniques to understanding biogeophysical signatures at LNAPL (light non-aqueous phase liquids) contaminated sites. A discussion on the physical and chemical basis for observable geophysical signatures from subsurface LNAPL distributions (Fig. 13) is given. The authors have suggested that loop-loop electromagnetic and RMT systems are promising electromagnetic techniques for future biogeophysical studies. A case study from a disused petroleum refinery site is described in which a loop-loop electromagnetic system detected high conductivities, apparently caused by ions released during the biodegradation of LNAPLs from a subsurface hydrocarbon plume.

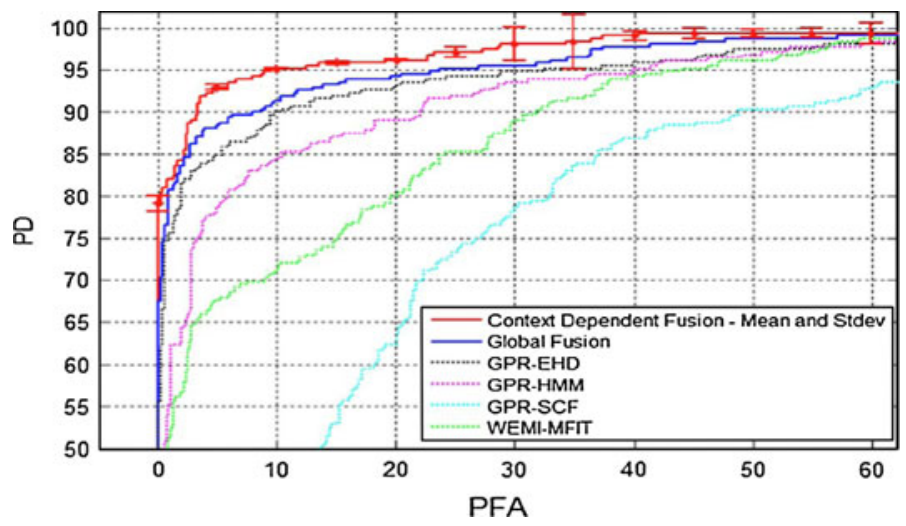

Fig. 12 Receiver performance curve showing probability of target detection $(P D)$ against probability of false alarm $(P F A)$ for a number of different GPR and EM data fusion strategies. Context-dependent fusion (red curve) shows the best performance because it provides the highest PD for a given PFA (after Frigui et al. 2008) 
Fig. 13 Soil moisture and LNAPL contamination distribution in the vadose zone. The LNAPL rapidly partitions into vapor, residual, free, and dissolved phases, as shown (after Atekwana and Atekwana 2010)

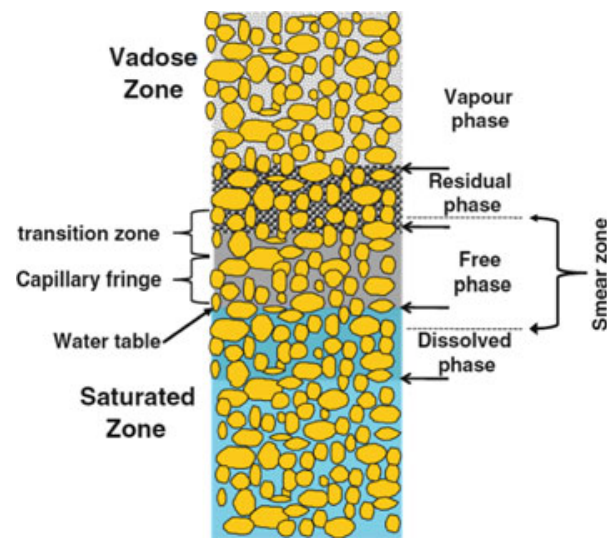

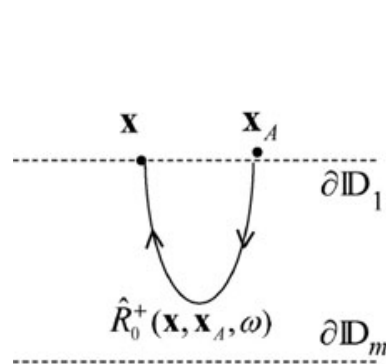

State $A$

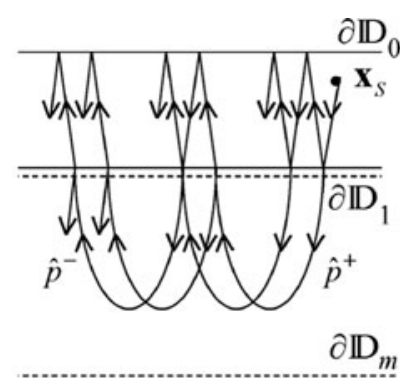

State $B$

Fig. 14 (left) Ideal propagation of an impulsive signal between two stations located at level 1; (right) the actual signal propagation paths can include effects such as multiple reflections from the free surface at level 0 (after Wapenaar et al. 2008). Used with permission

Seismologists have long been aware that Earth's elastic wave response at one location due to an impulsive source deployed at a second location (see Fig. 14) can be extracted from a cross-correlation of wavefields recorded at both locations. It has been conjectured of late that such an interferometric method might be applicable to marine controlled-source electromagnetics (CSEM) data interpretation. Fan and Snieder (2009) have shown, however, that CSEM interferometry using cross-correlation is impractical since it requires a large number of active sources to be deployed very close to the measurement locations. On the other hand, Wapenaar et al. (2008) have argued on theoretical grounds that interferometry of diffusive marine CSEM signals may be feasible for a variant of the method that utilizes a multidimensional deconvolution procedure rather than cross-correlation. A major attraction of diffusive interferometry is that it can potentially remove the contributions of the overlying air and seawater layers from marine CSEM data.

Butler (2009) has reviewed recent developments in freshwater and marine near-surface electrical and electromagnetic geophysical techniques. Early demonstration of the feasibility of seafloor near-surface electromagnetics centered on a towed coaxial magnetic dipole-dipole configuration that was capable of mapping porosity and other geotechnical 
Fig. 15 (top panel) A commercial loop-loop EM sensor and a GPR system deployed on a non-conductive boat, dimensions are in $\mathrm{m}$; (bottom panel) a riverine subbottom electromagnetic geophysical survey conducted in Turin, Italy (after Sambuelli et al. 2007)

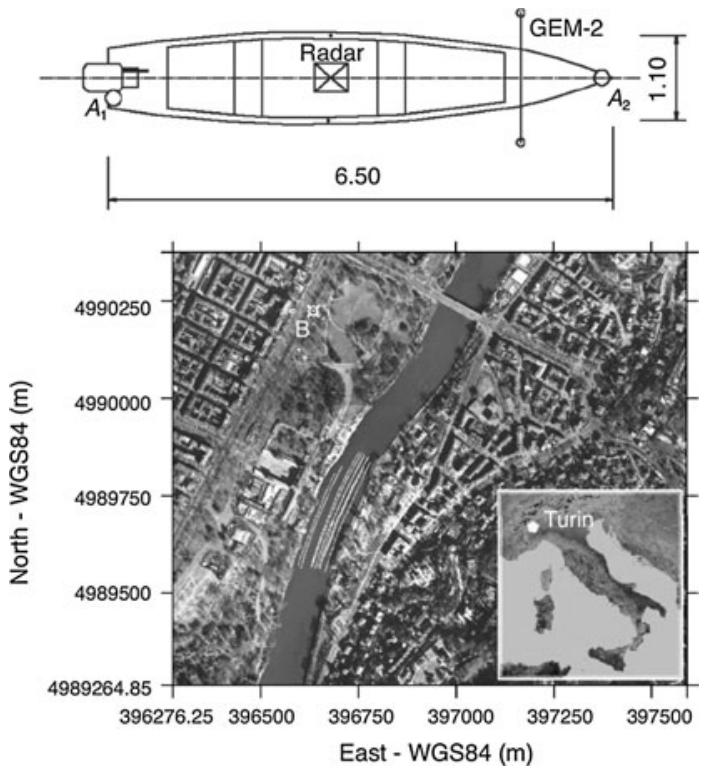

properties. Of late, this system has been applied to the study of coastal hydrological processes including freshwater and saline water exchanges between oceans and rivers. In addition to this, conventional terrestrial loop-loop systems have been floated on rivers or installed within non-conductive boats in order to map sub-bottom clays or zones of salinization underlying the fresh water (Fig. 15). A new compact electromagnetic system has recently been deployed on a remotely operated vehicle (ROV) for mapping massive sulfides immediately beneath the deep seafloor.

The electromagnetic induction method operates in the diffusive regime at low frequencies, such that electrical conductivity is much greater than the product of permittivity and frequency, $\sigma \gg \varepsilon \omega$, in which case the displacement currents that generate electromagnetic wave propagation effects can be safely ignored. In near-surface electromagnetic experiments conducted in resistive terrains at high frequencies, displacement currents can become important and their neglect could lead to artifacts in model reconstructions and incorrect geological interpretations. Kalscheuer et al. (2008) have suggested that the dielectric effect should be considered when its magnitude approaches the level of error in the measurements. As shown in Fig. 16, significant effects of displacement currents on the amplitudes and phases of 2-D RMT impedance data up to $300 \mathrm{kHz}$ acquired in highly resistive terrains are found in this contribution through the development and application of new 2-D modeling and inversion capabilities.

The capabilities of time-domain airborne electromagnetic (AEM) systems for mapping unexploded ordnance (UXO) have improved greatly in the past several years. AEM systems offer advantages over airborne magnetometry since the data are not greatly affected by magnetic soils or basalts and non-ferrous items can be detected. The performance characteristics of a new AEM system (Fig. 17) are outlined by Doll et al. (2010). The system has eight coincident transmitter/receiver loops mounted on a boom beneath a helicopter flown at several $\mathrm{m}$ altitude. Significant improvements over the past several years have been made in the noise reduction and data processing algorithms. Recent test results 

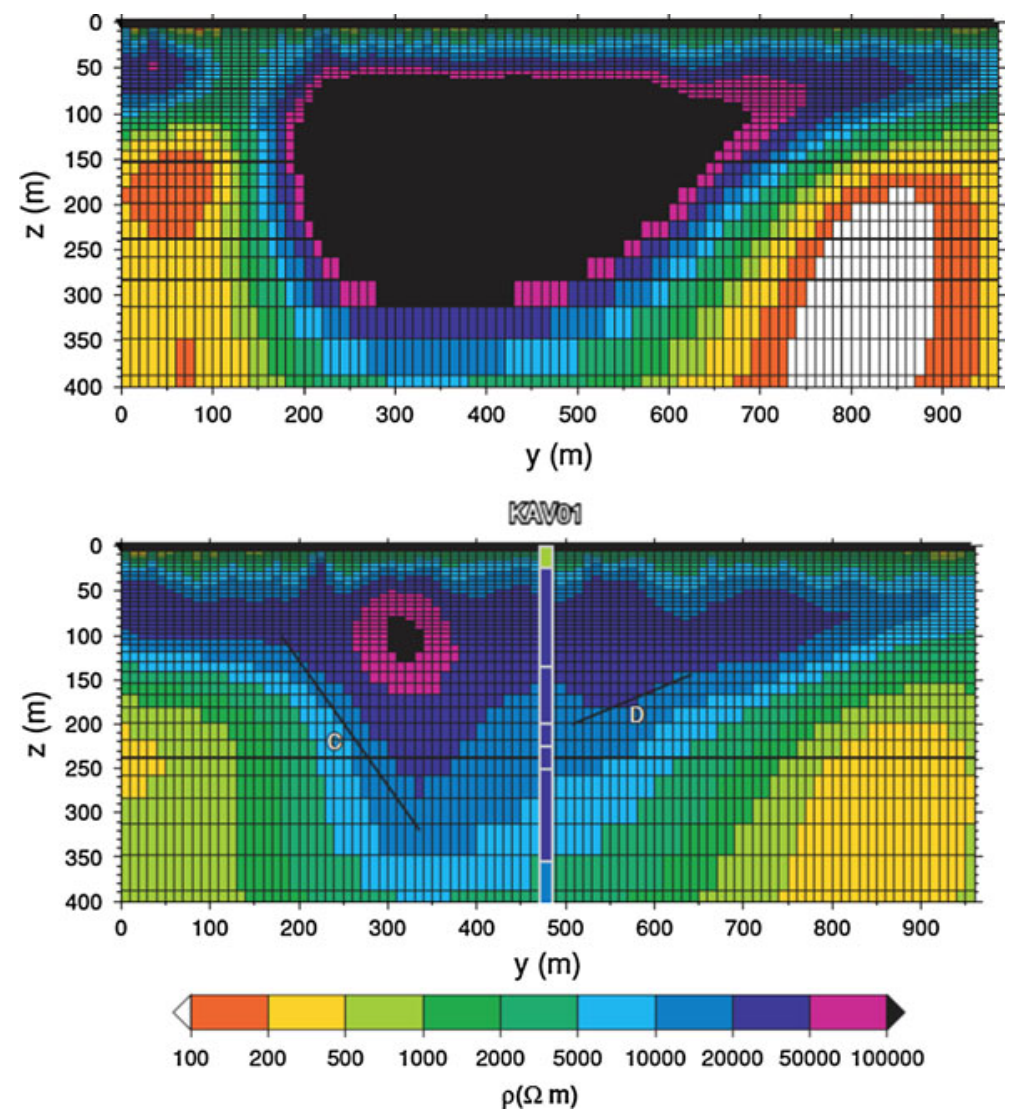

Fig. 16 A 2-D RMT inversion in resistive crystalline terrain neglecting displacement currents (top panel); inversion of the same data including the effects of displacement currents (bottom panel) (after Kalscheuer et al. 2008). Used with permission

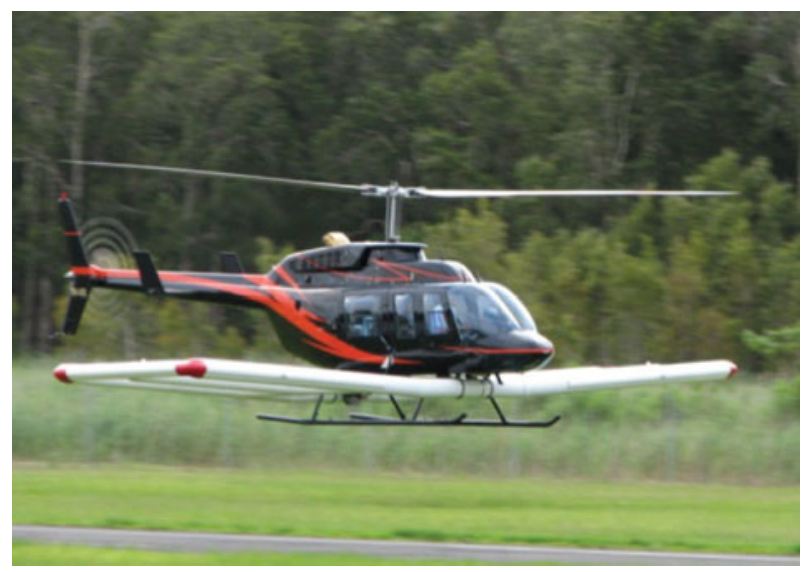

Fig. 17 The Batelle TEM-8 airborne system for UXO detection and classification (after Doll et al. 2010) 

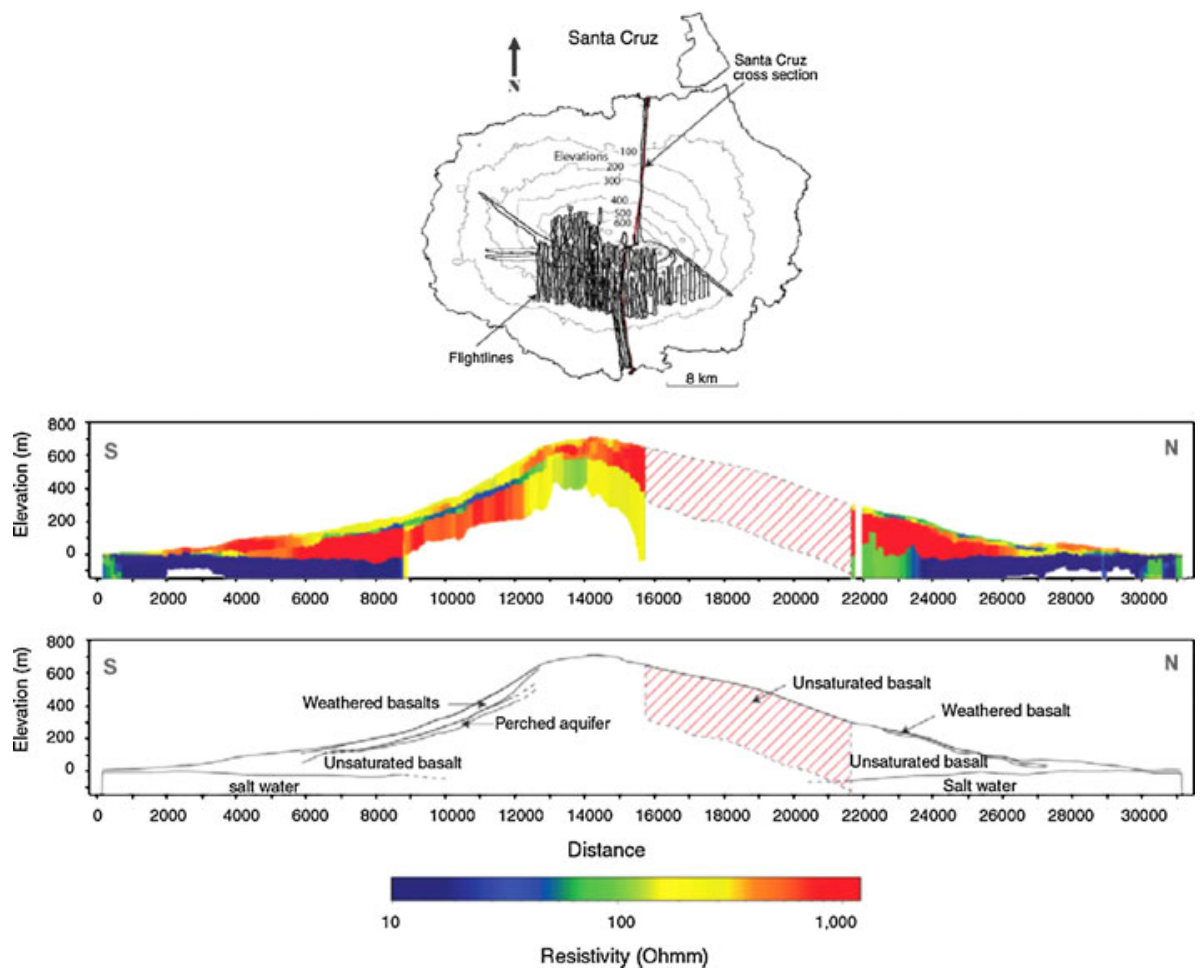

Fig. 18 (top panel) SkyTEM flight lines over Santa Cruz island. Contour levels in m a.s.l.; (middle panel) resistivity profile along the N-S cross-section; (bottom panel) hydrogeological interpretation of the AEM data (after Auken et al. 2009). Used with permission

from a seeded site indicated $99 \%$ probability of detection of an ordnance item within $1.5 \mathrm{~m}$ of its actual location and $98 \%$ within $1.0 \mathrm{~m}$.

\section{Selected Applications}

My search of the literature has revealed that the major areas of application of near-surface electromagnetic techniques can be broadly organized into hydrogeology, contamination, UXO and landmines, soils and agriculture, archeology, hazards and climate, and "other" applications. In this section of the review, I have chosen to highlight a representative case study from each of these application areas. A bibliography attached to the end of the review lists additional selected papers in each area.

The hydrogeology example is a case study by Auken et al. (2009). A helicopter transient AEM survey with $\sim 300 \mathrm{~m}$ penetration depth was carried out over a $190-\mathrm{km}^{2}$ area of Santa Cruz volcanic island in the Galapagos archipelago (Fig. 18). The island has few freshwater resources, a fast-growing population, and unique, pristine ecosystems. Very little, however, is known about the hydrogeology. The acquisition of geophysical data improves this understanding and assists in the development of effective water resource management strategies. The main exploration target is conductive zones perhaps indicative of water or clay confining layers that are located within the resistive $(>1,000 \Omega \mathrm{m})$ volcanic terrain. A 


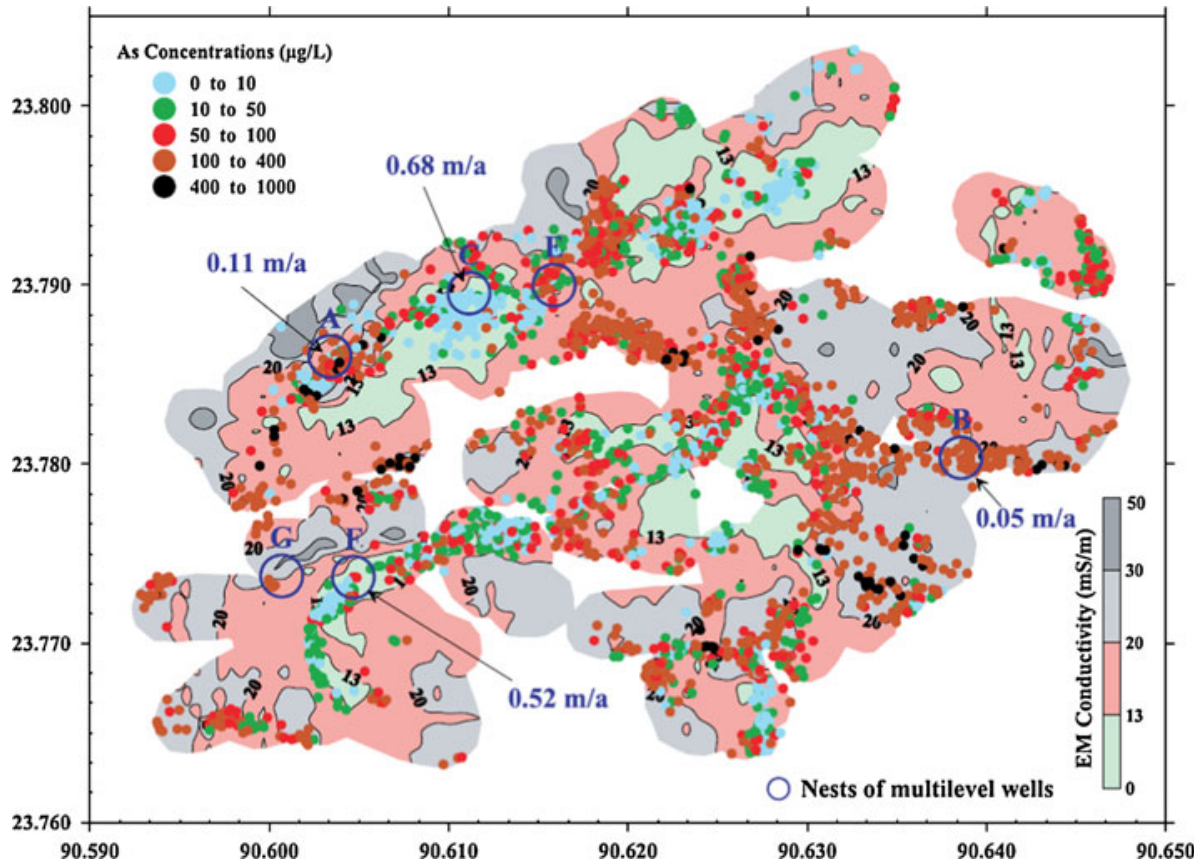

Fig. 19 A spatially continuous kriged map of EM34 apparent conductivity readings, along with arsenic concentration data from shallow wells, Bengal basin (after Aziz et al. 2008)

3-D spatially constrained series of 1-D local inversions is used to determine the subsurface conductivity structure. The northern leeward side of the island is found to exhibit very low conductivity and thus has a low hydrogeological potential. A perched aquifer at $\sim 80-100 \mathrm{~m}$ depth may exist on the windward side. The AEM inversions also suggest that intruded seawater underlies the periphery of the island. The geophysical data cannot resolve the presence of possible freshwater lenses above the saltwater.

The contamination example is an investigation into arsenic concentrations in Bangladesh by Aziz et al. (2008). It is well established that groundwater pumped from wells across the Bengal Basin often contains a hazardous (defined herein as $>50 \mu \mathrm{g} / \mathrm{L}$ ) level of arsenic. The source of the arsenic is difficult to ascertain in view of the strongly heterogeneous fluvio-deltaic geology of the region. A $25-\mathrm{km}^{2}$ survey area was chosen in which $\sim 5,000$ arsenic concentration values from shallow $(<22 \mathrm{~m})$ Holocene aquifers were available. Loop-loop frequency-domain electromagnetic data were acquired to discriminate subsurface zones of clays and sands in an attempt to better understand the observed spatial variability of the arsenic concentration data. About $18,500 \sigma_{\mathrm{a}}$ readings were made at 4-8 m station spacing along a number of transects, typically $100 \mathrm{~m}$ to $1 \mathrm{~km}$ in length, distributed across the survey area. A spatially continuous $\sigma_{\mathrm{a}}$ map was constructed by kriging (Fig. 19). It is found that $73 \%$ of the wells show non-hazardous arsenic levels in the areas of low $\sigma_{\mathrm{a}}<10 \mathrm{mS} / \mathrm{m}$ values, which are presumably sand-dominated regions. However, only $36 \%$ of the wells show non-hazardous arsenic levels in the high $\sigma_{\mathrm{a}}>10 \mathrm{~S} /$ $\mathrm{m}$, clay-dominated regions. The $\sigma_{\mathrm{a}}$ values were also found to correlate with the depth gradient of arsenic concentration within a well. These findings suggest that the clay- 
dominated areas are at higher risk, since groundwater recharge percolating downward through sandy soils tends to prevent arsenic concentrations from rising to hazardous levels.

The UXO case study is taken from Gasperikova et al. (2009). The cleanup of buried unexploded munitions is an expensive task; at most sites, $>99 \%$ of excavations are false alarms due to non-hazardous items. Development of new geophysical capabilities is needed to lower the false alarm rate while maintaining a high probability of detection. The electromagnetic response of a buried UXO approximates that due to a polarizable magnetic dipole. UXO targets are bodies of revolution characterized by a single major polarizability aligned with the long axis and two equal smaller transverse polarizabilities. This paper describes the performance of a new cart-mounted electromagnetic induction system of three orthogonal $1 \times 1 \mathrm{~m}$ loop transmitters transmitting a $340-\mu$ s half-sine pulse combined with eight pairs of embedded differential coil receivers measuring $\partial \mathrm{B}_{\mathrm{z}} / \partial t$ at $20-\mathrm{Hz}$ resonance frequency over a 1.26-ms measurement window. A statistical classification method is used for polarizability tensor retrieval. After testing and calibration, a survey at a military test site containing buried, identical 107-mm mortars was undertaken. All 56 mortars were identified while excavation of false alarms contributed to less than $20 \%$ of the total dig time.

An example from soils and agriculture is the paper by Robinson et al. (2009). A primary aim of time-lapse hydrogeophysics is to better understand subsurface hydrological processes by monitoring changes in geophysical images over time. The authors performed spatiotemporal loop-loop electromagnetic data acquisition across a $\sim$-ha agricultural field site in the Mekong floodplain, Cambodia. Each survey of $\sim 1 \mathrm{~m}$ penetration depth consisted of $\sim 1,000 \sigma_{\mathrm{a}}$ measurements on $\sim 25-30$ lines with $\sim 4$-m station spacing. Apparent conductivity $\sigma_{\mathrm{a}}$ was surveyed nine times over a period of 2 weeks, with an intensive rainfall event occurring between the first and second surveys. Spatially continuous $\sigma_{\mathrm{a}}$ maps were constructed by kriging. The maximum average $\sigma_{\mathrm{a}}$ value occurred 4-5 days after the rainfall event, providing an estimate of the water infiltration rate. The average $\sigma_{\mathrm{a}}$ value remained higher than its original value 3 weeks after the rainfall event, suggesting that the soil had not returned to its original dry state. Analysis of the time-lapse images indicated hydrologically important zones of water accumulation and depletion that are most likely related to clay content.

The archeological example is from Conyers et al. (2008) who have used loop-loop electromagnetic data to map the floodplains of meandering rivers at $\sim 2-6 \mathrm{~m}$ depth. This sedimentary environment presents challenges for traditional archeological prospection methods as cultural remains are often deeply buried, leaving no trace at the surface. Human settlement remains are often found in past topographic highs such as levees and terraces since they contain rich soils and are not subject to frequent flooding. Apparent conductivity $\sigma_{\mathrm{a}}$ maps derived from the geophysical data can be used to determine spatial variations in sands, gravels, clays, and organic matter. The resulting patterns are often suggestive of floodplain paleofeatures such as channels, point bars, levees, terraces, and oxbows. The geophysical images help the archeologist to reconstruct historic floodplain environments (Fig. 20). This information can then be used to guide a more efficient search for archeological remains. Case studies are presented from rivers in California, Texas, and Mississippi. The electromagnetic survey results indicated that $60-90 \%$ of the site areas do not warrant further archeological interest. Subsequent excavations of the more promising areas were successful in finding buried archeological remains at the Texas and Mississippi sites.

The hazards and climate example is from Haas et al. (2008) who used a combination of helicopter AEM and ground-based loop-loop electromagnetics to measure the thickness of perennial sea ice in the Weddell Sea as part of a larger investigation into the effects on the 


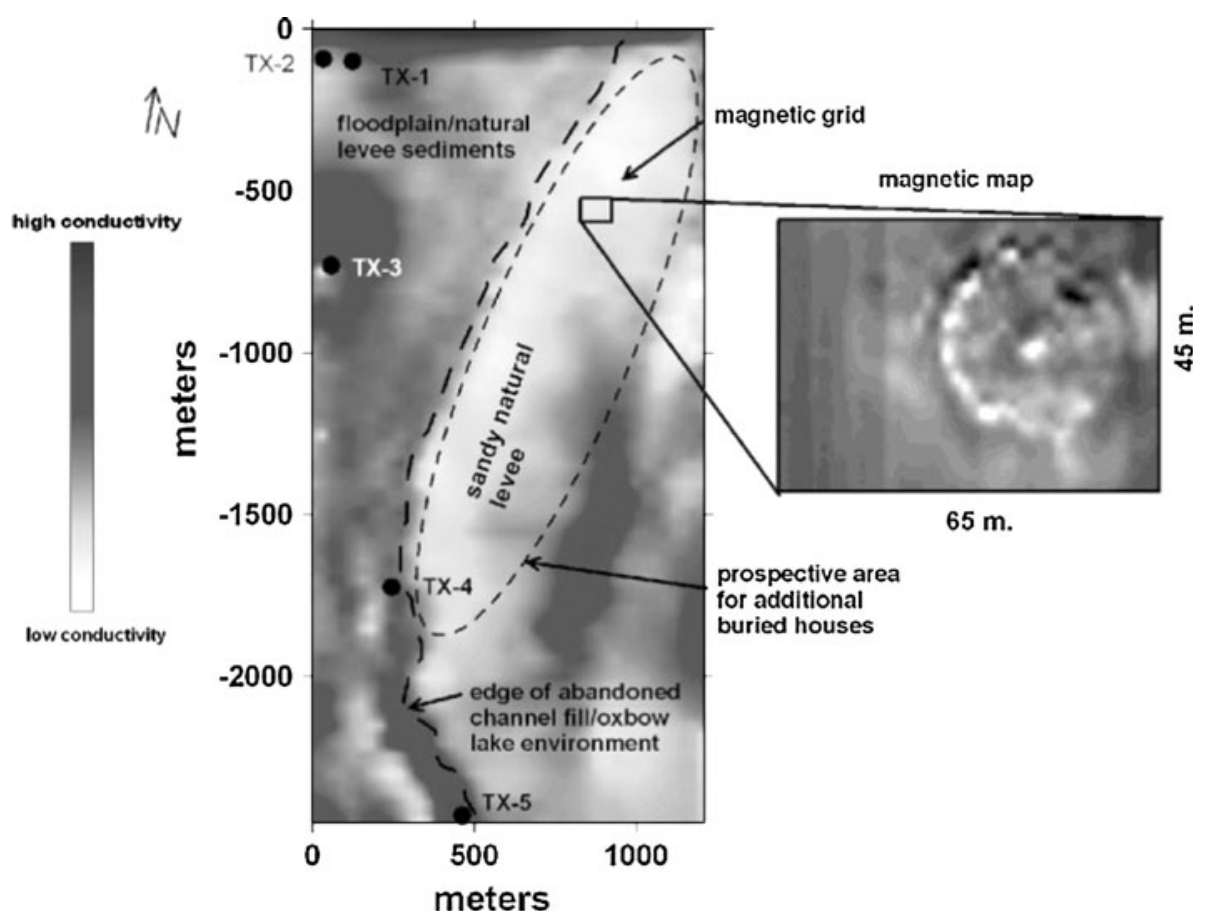

Fig. 20 (left) Plan-view distribution of electrical conductivity based on loop-loop EM data, along with interpretation of floodplain sedimentological structures; (right) magnetic map revealing a native American dwelling preserved within the natural levee (after Conyers et al. 2008). Used with permission

snow and ice cover during spring warming in Antarctica. The investigated ice floe is composed of snow, first-year, and second-year ice. Average thickness based on the AEM data is $3.01 \mathrm{~m}$ and $2.64 \mathrm{~m}$ based on the loop-loop data. The first-year ice thickness did not change during a 3-week period in the spring, while the second-year ice thickness decreased by $0.4 \mathrm{~m}$, perhaps as a result of bottom melt. Alignment of vertical brine channels within the ice is expected to cause horizontal electrical anisotropy with $\sigma_{\mathrm{v}}>\sigma_{\mathrm{h}}$ by almost an order of magnitude; however, the inductive measurements are insensitive to $\sigma_{\mathrm{v}}$. The apparent bulk conductivity increased from 37 to $97 \mathrm{mS} / \mathrm{m}$ during a warming of $\sim 2 \mathrm{C}$, while $\sigma_{\mathrm{h}}$ changed from 9 to $70 \mathrm{mS} / \mathrm{m}$. These changes are likely caused by increases in brine volume. The amount of ice thinning seen in the Antarctic perennial sea ice is much less than deduced from similar observations in the Arctic.

\section{Closing Remarks}

A glance at the reference list and bibliography appended to this review should leave no doubt that near-surface applied electromagnetic geophysics is currently experiencing an explosive period of growth. I have described some of the most notable recent advances in traditional topics and have introduced a few newly emergent techniques and exciting geoscience applications. The electromagnetic induction technique, along with its siblings DC resistivity, induced polarization, and ground-penetrating radar, will continue to grow in 
popularity among geoscientists over the next years and decades. The reasons are at least twofold. First, a wide variety of users including soil scientists, archeologists, hydrologists, volcanologists, and many others have already achieved tremendous successes in applying the method. Second, and more importantly, we are only just beginning to understand and exploit the rich information content that is available in electromagnetic datasets. Earth materials have essentially infinite complexity, which is readily confirmed simply by gazing upon a handful of soil. Electromagnetic methods, with broad opportunities to design new transmitters, receivers, and interpretation tools, offer possibilities unmatched elsewhere in geophysics to capture and understand the spatial complexity that lies buried beneath the surface.

Acknowledgments I thank the EM Induction Workshop committee for the opportunity to present this review. I am also grateful to Sofia Davydycheva and Richard Smith, respectively, for bringing to my attention some important logging and airborne electromagnetics papers. This paper was written while I was on sabbatical leave from Texas A\&M as a visiting professor at ETH, Zurich.

\section{References}

Abdu H, Robinson DA, Seyfried M, Jones SB (2008) Geophysical imaging of watershed subsurface patterns and prediction of soil texture and water holding capacity. Water Resour Res 44:2008WR007043

Abubakar A, Habashy TM, Druskin VL, Knizhnerman L, Alumbaugh D (2008) 2.5D forward and inverse modeling for interpreting low-frequency electromagnetic measurements. Geophysics 73:F165-F177

Asten MW, Duncan AC (2007) Fast approximate EM induction modeling of metallic and UXO targets using a permeable prism. J Appl Geophys 61:235-242

Atekwana EA, Atekwana EA (2010) Geophysical signatures of microbial activity at hydrocarbon contaminated sites: a review. Surv Geophys 31:247-283

Auken E, Violette S, d'Ozouville N, Deffontaines B, Sørensen KI, Viezzoli A, de Marsily G (2009) An integrated study of the hydrogeology of volcanic islands using helicopter borne transient electromagnetic: application in the Galápagos Archipelago. C R Geosci 341:899-907

Avdeev D, Knizhnik S (2009) 3D integral equation modeling with a linear dependence on dimensions. Geophysics 74:F89-F94

Aziz Z, van Geen A, Stute M, Versteeg R, Horneman A, Zheng Y, Goodbred S, Steckler M, Weinman B, Gavrieli I, Hoque MA, Shamsudduha M, Ahmed KM (2008) Impact of local recharge on arsenic concentrations in shallow aquifers inferred from the electromagnetic conductivity of soils in Araihazar, Bangladesh. Water Resour Res 44:2007WR006000

Bala J, Pieta A (2010) Validation of joint inversion of direct current and electromagnetic measurements. Acta Geophys 58:114-125

Boerner RU (2010) Numerical modelling in geo-electromagnetics: advances and challenges. Surv Geophys $31: 225-245$

Bréard A, Perrusson G, Lesselier D (2008) Hybrid differential evolution and retrieval of buried spheres in subsoil. IEEE Geosci Remote Sens Lett 5:788-792

Bréard A, Perrusson G, Lesselier D (2009) Low-frequency electromagnetic modeling of conductive obstacles buried in subsoil as coupled ellipsoids. Radio Sci 44:2008RS003939

Brenning A, Koszinski S, Sommer M (2008) Geostatistical homogenization of soil conductivity across field boundaries. Geoderma 143:254-260

Butler KE (2009) Trends in waterborne electrical and EM induction methods for high resolution sub-bottom imaging. Near Surf Geophys 7:241-246

Candansayar ME, Tezkan B (2008) Two-dimensional joint inversion of radiomagnetotelluric and direct current resistivity data. Geophys Prosp 56:737-749

Chen XD, O'Neill K, Grzegorczyk TM, Kong JA (2007) Spheroidal mode approach for the characterization of metallic objects using electromagnetic induction. IEEE Trans Geosci Remote Sens 45:697-706

Commer M, Newman GA (2008) New advances in three-dimensional controlled-source electromagnetic inversion. Geophys J Int 172:513-535

Conyers LB, Ernenwein EG, Grealy M, Lowe KM (2008) Electromagnetic conductivity mapping for site prediction in meandering river floodplains. Arch Prosp 15:81-91 
Cox LH, Wilson GA, Zhdanov MS (2010) 3D AEM inversion with a moving footprint: a case study for salt mapping at Bookpurnong, South Australia. In: Proceedings of SAGEEP 2010, Keystone

Davydycheva S (2010) 3D modeling of new-generation (1999-2010) resistivity logging tools. Lead Edge 29:780-789

Davydycheva S, Homan D, Minerbo G (2009) Triaxial induction tool with electrode sleeve: FD modeling in 3D geometries. J Appl Geophys 67:98-108

Decker KT, Everett ME (2009) Roughness of a layered geological medium and implications for interpretation of the transient electromagnetic response of a loop source. In: Proceedings of 22nd SAGEEP, Fort Worth

Doll WE, Bell DT, Gamey J, Beard LP, Sheehan JR, Norton J (2010) Performance metrics for state-of-theart airborne magnetic and electromagnetic systems for mapping and detection of unexploded ordnance. In: Proceedings of SPIE 7664

Druyts P, Das Y, Craeye C, Acheroy M (2009) Modeling the response of electromagnetic induction sensors to inhomogeneous magnetic soils with arbitrary relief. IEEE Trans Geosci Remote Sens 47:2627-2638

Endo M, Cuma M, Zhdanov MS (2008) A multigrid integral equation method for large-scale models with inhomogeneous backgrounds. J Geophys Eng 5:438-447

Endo M, Cuma M, Zhdanov MS (2009) Large-scale electromagnetic modeling for multiple inhomogeneous domains. Commun Comput Phys 6:269-289

Epov MI, Shurina EP, Nechaev OV (2007) 3D forward modeling of vector field for induction logging problems. Russ Geol Geophys 48:770-774

Epov MI, Antonov EY, Fedorov AI (2010) Effect of inclined conductivity anisotropy on frequency induction and TEM data. Russ Geol Geophys 51:317-321

Everett ME (2009) Transient electromagnetic response of a loop source over a rough geological medium. Geophys J Int 177:421-429

Fan Y, Snieder R (2009) Required source distribution for interferometry of waves and diffusive fields. Geophys J Int 179:1232-1244

Fraser DC, Hodges G (2007) Induction-response functions for frequency-domain electromagnetic mapping system for airborne and ground configurations. Geophysics 72:F35-F44

Frigui H, Zhang LJ, Gader PD (2010) Context-dependent multisensor fusion and its application to land mine detection. IEEE Trans Geosci Remote Sens 48:2528-2543

Gasperikova E, Smith JT, Morrison HF, Becker A, Kappler K (2009) UXO detection and identification based on intrinsic target polarizabilities - a case history. Geophysics 74:B1-B8

Haas C, Nicolaus M, Willmes S, Worby A, Flinspach D (2008) Sea ice and snow thickness and physical properties of an ice floe in the western Weddell Sea and their changes during spring warming. Deep Sea Res II 55:963-974

Hu WY, Abubakar A, Habashy TM (2009) Joint electromagnetic and seismic inversion using structural constraints. Geophysics 74:R99-R109

Huang H, Rudd J (2008) Conductivity-depth imaging of helicopter-borne TEM data based on a pseudolayer half-space model. Geophysics 73:F115-F120

Hue YK, Teixeira FL (2007) Numerical mode-matching method for tilted-coil antennas in cylindrically layered anisotropic media with multiple horizontal beds. IEEE Trans Geosci Remote Sens 45:2451-2462

Kadioglu S, Daniels JJ (2008) 3D visualization of integrated ground penetrating radar data and EM-61 data to determine buried objects and their characteristics. J Geophys Eng 5:448-456

Kalscheuer T, Pedersen LB, Siripunvaraporn W (2008) Radiomagnetotelluric two-dimensional forward and inverse modelling accounting for displacement currents. Geophys J Int 175:486-514

Knizhnerman L, Druskin V, Zaslavsky M (2009) On optimal convergence rate for the rational Krylov subspace reduction for electromagnetic problems in unbounded domains, SIAM J Numer Anal 47:953-971

Lee HO, Teixeira FL (2007) Cylindrical FDTD analysis of LWD tools through anisotropic dipping-layered earth media. IEEE Trans Geosci Remote Sens 45:383-388

Løseth LO, Ursin B (2007) Electromagnetic fields in planarly layered anisotropic media. Geophys J Int 170:44-80

McKenna SP, McKenna JR (2010) Modeling and analysis of the response of a triaxial, frequency-domain electromagnetic induction sensor to a buried linear conductor. Geophysics 75:F1-F14

Monteiro Santos FA, El-Kaliouby HM (2010) Comparative study of local versus global methods for 1D joint inversion of direct current resistivity and time domain electromagnetic data. Near Surf Geophys $8: 135-143$ 
Monteiro Santos FA, Triantafilis J, Bruzgulis KE, Roe JAE (2010) Inversion of multi configuration electromagnetic (DUALEM-421) profiling data using a one-dimensional laterally constrained algorithm. Vadose Zone J 9:117-125

Mulder WA, Wirianto M, Slob EC (2008) Time-domain modeling of electromagnetic diffusion with a frequency-domain code. Geophysics 73:F1-F8

Newman GA, Commer M, Carazzone JJ (2010) Imaging CSEM data in the presence of electrical anisotropy. Geophysics 75:F51-F61

Nobes DC (1996) Troubled waters: environmental applications of electrical and electromagnetic methods. Surv Geophys 17:393-454

Novo MS, da Silva LC, Teixeira FL (2007) Finite volume modeling of borehole electromagnetic logging in 3-D anisotropic formations using coupled scalar- vector potentials. IEEE Ant Wirel Propag Lett 6:549-552

Omeragic D, Habashy T, Chen YH, Polyakov V, Kuo CH, Altman R, Hupp D, Maeso C (2010) 3D reservoir characterization and well placement in complex scenarios using LWD directional EM measurements. Petrophysics 50:396-415

Pardo D, Torres-Verdín C, Nama MJ, Paszynski M, Calo VM (2008) Fourier series expansion in a nonorthogonal system of coordinates for the simulation of $3 \mathrm{D}$ alternating current borehole resistivity measurements. Comput Methods Appl Mech Eng 197:3836-3849

Pasion LR, Billings SD, Oldenburg DW (2008) Improving detection and discrimination of buried metallic objects in magnetic geologic settings by modeling the background soil response. In: SPIE proceedings, vol 6953, p 695310

Pellerin L (2002) Applications of electrical and electromagnetic methods for environmental and geotechnical investigations. Surv Geophys 23:101-132

Plessix RE, van der Sman P (2008) Regularized and blocky 3D controlled source electromagnetic inversion. In: Proceedings of PIERS 2008, pp 149-154

Plessix RE, Darnet M, Mulder WA (2007) An approach for 3D multisource, multifrequency CSEM modeling. Geophysics 72:SM177-SM184

Robinson DA, Lebron I, Kocar B, Phan K, Sampson M, Crook N, Fendorf S (2009a) Time-lapse geophysical imaging of soil moisture dynamics in tropical deltaic soils: An aid to interpreting hydrological and geochemical processes. Water Resour Res 45:2008WR006984

Sambuelli L, Leggieri S, Calzoni C, Porporato C (2007) Study of riverine deposits using electromagnetic methods at a low induction number. Geophysics 72:B113-B120

Shubitidze F, Karkashadze D, Barrowes B, Shamatava I, O’Neill K (2008) A new physics-based approach for estimating a buried object's location, orientation and magnetic polarization from EMI data. J Environ Eng Geophys 13:115-130

Singer BS (2008) Electromagnetic integral equation approach based on contraction operator and solution optimization in Krylov subspace. Geophys J Int 175:857-884

Singer BSh, Fainberg EB (2007) Fast imaging and inversion of on and off shore electromagnetic data. Tectonophysics 445:81-97

Smith JT, Morrison HF, Doolittle LR, Tseng HW (2007) Multi-transmitter multi-receiver null coupled systems for inductive detection and characterization of metallic objects. J Appl Geophys 61:227-234

Song LP, Oldenburg DW, Pasion LR, Billings SD (2008a) Adaptive focusing for source localization in EMI sensing of metallic objects: a preliminary assessment. J Environ Eng Geophys 13:131-145

Song LP, Shubitidze F, Pasion LR, Oldenburg DW, Billings SD (2008b) Computing transient electromagnetic responses of a metallic object using a spheroidal excitation approach. IEEE Geosci Remote Sens Lett 5:359-363

Stalnaker J, Miller E (2007) Particle swarm optimization as an inversion tool for a nonlinear UXO model. In: Proceedings of IGARSS, pp 432-435

Streich R (2009) 3D finite-difference frequency-domain modeling of controlled-source electromagnetic data: direct solution and optimization for high accuracy. Geophysics 74:F95-F105

Sun XY, Nie Z (2008) 3-D modeling of electromagnetic induction in anisotropy media using finite element method. In: IEEE antennas and propagation international symposium, pp 707-710

Swidinsky A, Edwards RN (2009) The transient electromagnetic response of a resistive sheet: straightforward but not trivial. Geophys J Int 179:1488-1498

Swidinsky A, Edwards RN (2010) The transient electromagnetic response of a resistive sheet: an extension to three dimensions. Geophys J Int 182:663-674

Tarokh AB, Miller EL (2007) Subsurface sensing under sensor positional uncertainty. IEEE Trans Geosci Remote Sens 45:675-688

Tezkan B (1999) A review of environmental applications of quasi-stationary electromagnetic techniques. Surv Geophys 20:279-308 
Triantafilis J, Buchanan SM (2009) Identifying common near-surface and subsurface stratigraphic units using EM34 signal data and fuzzy k-means analysis in the Darling River valley. Austr J Earth Sci 56:535-558

Vallée MA, Smith RS (2009) Inversion of airborne time-domain electromagnetic data to a 1D structure using lateral constraints. Near Surf Geophys 7:63-71

van den Berg PM, Abubakar A, Habashy TM (2008) An efficient 3D integral equation method for computation of electromagnetic wavefields in a layered configuration containing inhomogeneous objects. In: Proceedings of PIERS 2008, pp 11-16

Viezzoli A, Christiansen AV, Auken E, Sørensen K (2008) Quasi-3D modeling of airborne TEM data by spatially constrained inversion. Geophysics 73:F105-F113

Walker SE, Pasion LR, Oldenburg DW, Billings SD (2007) Investigating the effect of data quality on time domain electromagnetic discrimination. J Appl Geophys 61:254-278

Wang H, Tao H, Yao J, Chen G (2008a) Fast multiparameter reconstruction of multicomponent induction well-logging datum in a deviated well in a horizontally stratified anisotropic formation. IEEE Trans Geosci Remote Sens 46:1525-1534

Wang H, So P, Yang S, Hoefer WJR, Du H (2008b) Numerical modeling of multicomponent induction welllogging tools in the cylindrically stratified anisotropic media. IEEE Trans Geosci Remote Sens 46:1134-1147

Wang GL, Torres-Verdín C, Gianzero S (2009) Fast simulation of triaxial borehole induction measurements acquired in axially symmetrical and transversely isotropic media. Geophysics 74:E233-E249

Wapenaar K, Slob E, Snieder R (2008) Seismic and electromagnetic controlled-source interferometry in dissipative media. Geophys Prosp 56:419-434

Wei MH, Scott WR Jr, McClellan JH (2010) Robust estimation of the discrete spectrum of relaxations for electromagnetic induction responses. IEEE Trans Geosci Remote Sens 48:1169-1179

Weiss CJ, Everett ME (2007) Anomalous diffusion of electromagnetic eddy currents in geological formations. J Geophys Res 112:2006JB00475

Weller U, Zipprich M, Sommer M, Zu Castell W, Wehrhan M (2007) Mapping clay content across boundaries at the landscape scale with electromagnetic induction. Soil Sci Soc Am J 71:1740-1747

Wilson GA, Cox LH, Zhdanov MS (2010) Practical 3D inversion of entire airborne electromagnetic surveys. ASEG Preview, June, 29-33

Yegorov IV (2009) 3-D numerical modeling of an electromagnetic field in geoelectrics using the Trefftz method. Izv Phys Solid Earth 45:812-821

Yin C, Hodges G (2009) Wire-loop surface conductor for airborne EM system testing. Geophysics 74:F1-F8

Yuan N, Nie XC, Liu R, Qiu CW (2010) Simulation of full responses of a triaxial induction tool in a homogeneous biaxial anisotropic formation. Geophysics 75:E101-E114

Zhang B, O'Neill K, Kong JA, Grzegorczyk TM (2008) Support vector machine and neural network classification of metallic objects using coefficients of the spheroidal MQS response modes. IEEE Trans Geosci Remote Sens 46:159-161

Zhdanov MS, Dmitriev VI, Gribenko AV (2007) Integral electric current method in 3-D electromagnetic modeling for large conductivity contrast. IEEE Trans Geosci Remote Sens 45:1282-1290

Zhong L, Li J, Bhardwaj A, Shen LC, Liu RC (2008) Computation of triaxial induction logging tools in layered anisotropic dipping formations. IEEE Trans Geosci Remote Sens 46:1148-1163

\section{Bibliography: Hydrogeology}

Al-Garni MA, El-Kaliouby HM (2010) Delineation of saline groundwater and sea water intrusion zones using transient electromagnetic (TEM) method, Wadi Thuwal area, Saudi Arabia. Arab J Geosci. doi: 10.1007/s12517-009-0094-5

Auken E, Violette S, d'Ozouville N, Deffontaines B, Sørensen KI, Viezzoli A, de Marsily G (2009b) An integrated study of the hydrogeology of volcanic islands using helicopter borne transient electromagnetic: application in the Galápagos Archipelago. C R Geosci 341:899-907

Baldridge WS, Cole GL, Robinson BA, Jiracek GR (2007) Application of time-domain airborne electromagnetic induction to hydrogeologic investigations on the Pajarito Plateau, New Mexico, USA. Geophysics 72:B31-B45

Buchanan S, Triantafilis J (2009) Mapping water table depth using geophysical and environmental variables. Ground Water 47:80-96

Callegary JB, Leenhouts JM, Paretti NV, Jones CA (2007a) Rapid estimation of recharge potential in ephemeral stream channels using electromagnetic methods, and measurements of channel and vegetation characteristics. J Hydrol 344:17-31 
Callegary JB, Ferre TPA, Groom RW (2007b) Vertical spatial sensitivity and exploration depth of lowinduction-number electromagnetic-induction instruments. Vadose Zone J 6:158-167

Duque C, Calvache ML, Pedrera A et al (2008) Combined time domain electromagnetic soundings and gravimetry to determine marine intrusion in a detrital coastal aquifer (southern Spain). J Hydrol 349:536-547

Falgas E, Ledo J, Marceullo A, Queralt P (2009) Monitoring freshwater-seawater interface dynamics with audiomagnetoelluric data. Near Surf Geophys 7:391-399

Kafri U, Goldman M, Levi E (2008) The relationship between saline groundwater within the Arava Rift Valley in Israel and the present and ancient base levels as detected by deep geoelectromagnetic soundings. Environ Geol 54:1435-1445

Levi E, Goldman M, Hadad A et al (2008) Spatial delineation of groundwater salinity using deep time domain electromagnetic geophysical measurements: a feasibility study. Water Resour Res 44, art.no. W12404

Morin RH, LeBlanc DR, Troutman BM (2010) The influence of topology on hydraulic conductivity in a sand-and-gravel aquifer. Ground Water 48:181-190

Robinson DA, Binley A, Crook N, Day-Lewis FD, Ferré TPA, Grauch VJS, Knight R, Knoll M, Lakshmi V, Miller R, Nyquist J, Pellerin L, Singha K, Slater L (2008a) Advancing process-based watershed hydrological research using near-surface geophysics: a vision for, and review of, electrical and magnetic geophysical methods. Hydrol Process 22:3604-3635

Viezzoli A, Tosi L, Teatini P, Silvestri S (2010) Surface water-groundwater exchange in transitional coastal environments by airborne electromagnetics: the Venice Lagoon example. Geophys Res Lett 37:L01402

Zhu Q, Lin HS (2009) Simulation and validation of concentrated subsurface lateral flow paths in an agricultural landscape. Hydrol Earth Syst Sci 13:1503-1518

\section{Contamination}

Coria D, Bongiovanni V, Bonomo N, de la Vega M, Garea MT (2009) Hydrocarbon contaminated soil: geophysical-chemical methods for designing remediation strategies. Near Surf Geophys 7:227-236

Hoque MA, Khan AA, Shamsudduha M, Hossain MS, Islam T, Chowdhury SH (2009) Near surface lithology and spatial variation of arsenic in the shallow groundwater: southeastern Bangladesh. Environ Geol 56:1687-1695

Jin S, Fallgren P, Cooper J, Morris J, Urynowicz M (2008a) Assessment of diesel contamination in groundwater using electromagnetic induction geophysical techniques. J Environ Sci Health A 43:584-588

Jin S, Fallgren PH, Morris JM, Cooper JS (2008b) Source treatment of acid mine drainage at a backfilled coal mine using remote sensing and biogeochemistry. Water Air Soil Pollut 188:205-212

Martinelli P, Duplaá MC (2008) Laterally filtered 1D inversions of small-loop, frequency-domain EMI data from a chemical waste site. Geophysics 73:F143-F149

Martinelli HP, Osella AM (2010) Small-loop electromagnetic induction for environmental studies at industrial plants. J Geophys Eng 7:91-104

Paine JG, Nance HS, Collins EW, Niemann KL (2007) Quantifying contributions to stream salinity using electromagnetic induction and hydrochemistry in a small Texas coastal-plain basin. Appl Geochem 22:2207-2224

Paine JG, Collins EW, Nance HS, Niemann KL (2009) Combining airborne electromagnetic induction and hydrochemistry to quantify salinity contributions to a large stream basin, Colorado River, Texas, USA. Near Surf Geophys 7:271-282

Rucker DF (2010) The application of magnetic gradiometry and electromagnetic induction at a former radioactive waste disposal site. Waste Manage Res 28:364-372

Sherriff BL, Ferguson IJ, Gupton MW, van Gulck JF, Sidenko N, Priscu C, Perez-Flores M, Gomez-Trevino E (2009) A geophysical and geotechnical study to determine the hydrological regime of the central Manitoba gold mine tailings deposit. Can Geotech J 46:69-80

Sudha B, Tezkan M, Israil D, Singhal C, Rai J (2010) Geoelectrical mapping of aquifer contamination: a case study from Roorkee, India. Near Surf Geophys 8:33-42

\section{UXO and Landmines}

Aliamiri A, Stalnaker J, Miller EL (2007) Statistical classification of buried unexploded ordnance using nonparametric prior models. IEEE Trans Geosci Remote Sens 45:2794-2806 
Benavides A, Everett ME (2007) Non-linear inversion of controlled source multi-receiver electromagnetic induction data for unexploded ordnance using a continuation method. J Appl Geophys 61:243-253

Benavides A, Everett ME, Pierce C (2009) Unexploded ordnance discrimination using time-domain electromagnetic induction and self-organizing maps. Stoch Environ Res Risk Assess 23:169-179

Beran L, Oldenburg DW (2008) Selecting a discrimination algorithm for unexploded ordnance remediation. IEEE Trans Geosci Remote Sens 46:2547-2557

Billings SD, Pasion LR, Beran L, Lhomme N, Song LP, Oldenburg DW, Kingdon K, Sinex D, Jacobson J (2010) Unexploded ordnance discrimination using magnetic and electromagnetic sensors: case study from a former military site. Geophysics 75:B103-B114

Fails EB, Torrione PA, Scott WR, Collins LM (2008) Performance comparison of frequency domain quadrupole and dipole electromagnetic induction sensors in a landmine detection application. SPIE Proc 6953:695304

Ghvedashvili G, Kakulia D, Shubitidze F (2010) Investigation of EMI response for magnetically susceptible and conductive rough surfaces. In: Proceedings of DIPED-2009, pp 49-52

Grzegorczyk TM, Zhang B, Kong JA, Barrowes BE, O'Neill K (2008) Electromagnetic induction from highly permeable and conductive ellipsoids under arbitrary excitation: application to the detection of unexploded ordnances. IEEE Trans Geosci Remote Sens 46:1164-1176

He L, Ji S, Scott WR, Carin L (2007) Adaptive multimodality sensing of landmines. IEEE Trans Geosci Remote Sens 45:1756-1774

Huang HP, San Filipo B, Oren A et al (2007) Coaxial coil towed EMI sensor array for UXO detection and characterization. J Appl Geophys 61:217-226

Liu Q, Liao X, Carin L (2008) Detection of unexploded ordnance via efficient semisupervised and active learning. IEEE Trans Geosci Remote Sens 46:2558-2567

Mahmoudi M, Tan SY (2009) Depth detection of conducting marine mines via eddy-current and current channeling response. Prog Electromag Res 90:287-307

O’Neill K, Fernández JP (2009) Electromagnetic methods for UXO discrimination. In: Byrnes J (ed) Unexploded ordnance detection and mitigation. Springer, Berlin, pp 197-221

Pasion LR, Billings SD, Oldenburg DW, Walker SE (2007) Application of a library based method to time domain electromagnetic data for the identification of unexploded ordnance. J Appl Geophys 61:279-291

Pasion LR, Billings SD, Kingdon KA, Oldenburg DW, Lhomme N, Jacobson J (2008) Cooperative inversion of time domain electromagnetic and magnetometer data for the discrimination of unexploded ordnance. J Eng Environ Geophys 13:193-210

Robledo L, Carrasco M, Mery D (2009) A survey of land mine detection technology. Int J Remote Sens 30:2399-2410

Scott WR (2008) Broadband electromagnetic induction sensor for detecting buried landmines. In: Proceedings of IGARSS-2007, pp 22-25

Shubitidze F, O’Neill K, Barrowes BE, Shamatava I, Fernández JP, Sun K, Paulsen KD (2007) Application of the normalized surface magnetic charge model to UXO discrimination in cases with overlapping signals. J Appl Geophys 61:292-303

Shubitidze F, Demidenko E, Barrowes BE, Shamatava I, Fernández JP, O’Neill K (2008a) Combining dipole and mixed model approaches for UXO discrimination. SPIE Proc 6953:695305

Shubitidze F, Barrowes B, Shamatava I, Fernández JP, O’Neill K (2008b) Underwater UXO detection and discrimination: understanding EMI scattering phenomena in a conducting environment. SPIE Proc 6953:69530M

Shubitidze F, Fernandez JP, Shamatava I, Pasion LR, Barrowes BE, O'Neill K (2010) Application of the normalized surface magnetic source model to a blind unexploded ordnance discrimination test. ACES J 25:89-98

Stanley RJ, Ho KC, Gader P et al (2007) Land mine and clutter object discrimination using wavelet and time domain spatially distributed features from metal detectors and their fusion with GPR features for handheld units. Circuits Syst Signal Proc 26:165-191

Sun K, O'Neill K, Barrowes BE, Shubitidze F, Shamatava I, Fernandez JP, Paulsen KD (2007) Data-derived SEA for time domain EMI sensing of UXO. In: PIERS 2007 proceedings, pp 26-30

Throckmorton CS, Tantum SL, Tan Y, Collins LM (2007) Independent component analysis for UXO detection in highly cluttered environments. J Appl Geophys 61:304-317

Williams D, Yu Y, Kennedy L, Zhu X, Carin L (2007a) A bivariate Gaussian model for unexploded ordnance classification with EMI data. IEEE Geosci Remote Sens Lett 4:629-633

Williams D, Wang C, Liao X, Carin L (2007b) Classification of unexploded ordnance using incomplete multisensor multiresolution data. IEEE Trans Geosci Remote Sens 45:2364-2373 
Zeng ZF, Huang HP, Liu FS (2009) Identifying landmines by incorporating measurement uncertainties into EMIS library and decision threshold. J Environ Eng Geophys 14:39-46

\section{Soils and Agriculture}

Amezketa E, del Valle de Lersundi J (2008) Soil classification and salinity mapping for determining restoration potential of cropped riparian areas. Land Degrad Dev 19:153-164

Barbiéro L, Parate HR, Descloitres M, Bost A, Furian S, Kumar MSM, Kumar C, Braun JJ (2007) Using a structural approach to identify relationships between soil and erosion in a semi-humid forested area, South India. Catena 70:313-329

Besson A, Cousin I, Bourennane H, Nicoullaud B, Pasquier C, Richard G, Dorigny A, King D (2010) The spatial and temporal organization of soil water at the field scale as described by electrical resistivity measurements. Eur J Soil Sci 61:120-132

Cockx L, Van Meirvenne M, De Vos B (2007) Using the EM38DD soil sensor to delineate clay lenses in a sandy forest soil. Soil Sci Soc Am J 71:1314-1322

Cockx L, Van Meirvenne M, Vitharana UWA, Verbeke LPC, Simpson D, Saey T, Van Coillie FMB (2009) Extracting topsoil information from EM38DD sensor data using a neural network approach. Soil Sci Soc Am J 73:1-8

Cousin I, Besson A, Bourennane H, Pasquier C, Nicoullaud B, King D, Richard G (2009) From spatialcontinuous electrical resistivity measurements to the soil hydraulic functioning at the field scale. C R Geosci 341:859-867

Gebbers R, Luck E, Dabas M, Domsch H (2009) Comparison of instruments for geoelectric soil mapping at the field scale. Near Surf Geophys 7:179-190

Harvey O, Morgan CLS (2009) Predicting regional-scale soil variability using a single calibrated apparent soil electrical conductivity model. Soil Sci Soc Am J 73:164-169

Kuhn J, Brenning A, Wehrhan M, Koszinski S, Sommer M (2009) Interpretation of electrical conductivity patterns by soil properties and geological maps for precision agriculture. Precis Agric 10:490-507

Martinez G, Vanderlinden K, Ordóñez R, Muriel JL (2009) Can apparent electrical conductivity improve the spatial characterization of soil organic carbon? Vadose Zone J 8:586-593

Robinson DA, Abdu H, Jones SB, Seyfried M, Lebron I, Knight R (2008) Eco- geophysical imaging of watershed-scale soil patterns links with plant community spatial patterns. Vadose Zone J 7:1132-1138

Robinson DA, Lebron I, Kocar B, Phan K, Sampson M, Crook N, Fendorf S (2009) Time-lapse geophysical imaging of soil moisture dynamics in tropical deltaic soils: an aid to interpreting hydrological and geochemical processes. Water Resour Res 45:2008WR006984

Saey DS, Vermeersch H, Cockx L, Van Meirvenne M (2009) Comparing the EM38DD and DUALEM-21S sensors for depth-to-clay mapping. Soil Sci Soc Am J 73:7-12

Triantafilis J, Buchanan SM (2010) Mapping the spatial distribution of subsurface saline material in the Darling River valley. J Appl Geophys 70:144-160

Triantafilis J, Monteiro Santos FA (2009) 2-dimensional soil and vadose-zone representation using an EM38 and EM34 and a laterally constrained inversion model. Austr J Soil Res 47:809-820

Triantafilis J, Kerridge B, Buchanan SM (2009a) Digital soil-class mapping from proximal and remotely sensed data at the field level. Agron J 101:841-853

Triantafilis J, Mitchell S, Lesch B, La Lau K, Buchanan SM (2009b) Field level digital soil mapping of cation exchange capacity using electromagnetic induction and a hierarchical spatial regression model. Austr J Soil Res 47:651-663

Urdanoz V, Amezketa E, Clavería I, Ochoa V, Aragüés R (2008) Mobile and georeferenced electromagnetic sensors and applications for salinity assessment. Spanish J Agric Res 6:469-478

Valckx J, Cockx L, Wauters J, Van Meirvenne M, Govers G, Hermy M, Muys B (2009) Within-field spatial distribution of earthworm populations related to species interactions and soil apparent electrical conductivity. Appl Soil Ecol 41:315-328

Viezzoli A, Auken E, Munday T (2009) Spatially constrained inversion for quasi 3D modelling of airborne electromagnetic data-an application for environmental assessment in the Lower Murray Region of South Australia. Explor Geophys 40:173-183

Vitharana UWA, Van Meirvenne M, Simpson D, Cockx L, De Baerdemaeker J (2008) Key soil and topographic properties to delineate potential management classes for precision agriculture in the European loess area. Geoderma 143:206-215 


\section{Archaeology}

Bongiovanni MV, Bonomo N, de la Vega M, Martino L, Osella A (2008) Rapid evaluation of multifrequency EMI data to characterize buried structures at a historical Jesuit Mission in Argentina. J Appl Geophys 64:37-46

Creasman PP, Vining B, Koepnick S, Doyle N (2009) An exploratory geophysical survey at the pyramid complex of Senwosret III at Dahshur, Egypt, in search of boats. Int J Nautical Arch 38:386-399

Nobes DC (2007) Effect of grain size on the geophysical responses of indigenous burial sites. In: Proceedings of EAGE Near-Surf. 2007, Istanbul

Nobes DC, Wallace LR (2007) Geophysical imaging of an early 19th century colonial defensive blockhouse. In: Proceedings of EAGE Near-Surf 2007, Istanbul

Simpson D, Lehouck A, Van Meirvenne M, Bourgeois J, Thoen E, Vervloet J (2008) Geoarchaeological prospection of a medieval manor in the Dutch Polders using an electromagnetic induction sensor in combination with soil augerings. Geoarchaeology 23:305-319

Simpson D, van Meirvenne M, Saey T, van Meersch H, Bourgeois J, Le Houck A, Cockx L, Vitharana UWA (2009) Evaluating the multiple coil configurations of the EM38DD and DUALEM-21S sensors to detect archaeological anomalies. Arch Prosp 16:91-102

Thiesson J, Dabas M, Flageul S (2009) Detection of resistive features using towed Slingram electromagnetic induction instruments. Arch Prosp 16:103-109

Verdonck L, Simpson D, Cornelis WM, Plyson A, Bourgeois J, Docter R, van Meirvenne M (2009) Groundpenetrating radar survey over Bronze Age circular monuments on a sandy soil, complemented with electromagnetic induction and fluxgate gradiometer data. Arch Prosp 16:193-202

\section{Hazards and Climate}

Druckenmiller ML, Eicken H, Johnson MA, Pringle DJ, Williams CC (2009) Toward an integrated coastal sea-ice observatory: system components and a case study at Barrow, Alaska. Cold Regions Sci Tech $56: 61-72$

Guo J, Sun B, Tian G (2007) The application of electromagnetic-induction on the measurement of sea ice thickness in the Antarctic. Appl Geophys 4:214-220

Haas C, Lobach J, Hendricks S, Rabenstein L, Pfaffling A (2009) Helicopter- borne measurements of sea ice thickness, using a small and lightweight, digital EM system. J Appl Geophys 67:234-241

McLeod MK, Slavich PG, Irhas Y, Moore N, Rachman A, Ali N, Iskandar T, Hunt C, Caniago C (2010) Soil salinity in Aceh after the December 2004 Indian Ocean tsunami. Agric Water Manag 97:605-613

Saey T, Simpson D, Vitharana UWA, Vermeersch H, Vermang J, Van Meirvenne M (2008) Reconstructing the paleotopography beneath the loess cover with the aid of an electromagnetic induction sensor. Catena 74:58-64

Schmutz M, Guérin R, Andrieux P, Maquaire O (2009) Determination of the 3D structure of an earthflow by geophysical methods: the case of Super Sauze, in the French southern Alps. J Appl Geophys 68:500-507

Sharma SP, Anbarasu K, Gupta S, Sengupta A (2010) Integrated very low frequency EM, electrical resistivity, and geological studies on the Lanta Khola landslide, North Sikkim, India. Landslides 7:43-53

Shirasawa K, Eicken H, Tateyama K, Takatsuka T, Kawamura T (2009) Sea-ice- thickness variability in the Chukchi Sea, spring and summer 2002-2004. Deep Sea Res II 56:1182-1200

Zach JJ, Brauti K (2009) Methane hydrates in controlled-source electromagnetic surveys-analysis of a recent data example. Geophys Prosp 57:601-614

Zhao L, Geng JH, Zhang S, Yang D (2008) 1-D Controlled source electromagnetic forward modeling for marine gas hydrates studies. Appl Geophys 5:121-126

\section{Other Applications}

Antonov EY, Shein AN (2008) Improving inversion quality for IP-affected TDEM data. Russ Geol Geophys 49:790-802

Bastani M, Malehmir A, Ismail N, Pedersen LB, Hedjazi F (2009) Delineating hydrothermal stockwork copper deposits using controlled-source and radio-magnetotelluric methods: a case study from northeast Iran. Geophysics 74:B167-B181 
Chelovechkov AI, Chistoserdov BM, Baidikov SV (2008) A two-loop frequency-domain electromagnetic induction system for detection of anomalous objects. Russ Geol Geophys 49:628-632

Dolgun AA, Shurina EP, Epov MI (2009) Propagation of electromagnetic waves from an induction source in media with time-dependent conductivity and permittivity. Russ Geol Geophys 50:983-990

Ellis M, Evans RL, Hutchinson D, Hart P, Gardner J, Hagen R (2008) Electromagnetic surveying of seafloor mounds in the northern Gulf of Mexico. Mar Petrol Geol 25:960-968

Epov MI, Morozova GM (2010) TEM soundings in magnetic media. Russ Geol Geophys 51:204-208

Lei D, Zhao G, Yang Z, Zhao F, Li X (2008) An application of CSAMT to a geological investigation for railway route selection. Near Surf Geophys 6:315-318

MacLennan K, Li Y (2010) Signal extraction from 4D transient electromagnetic surveys using the equivalent source method. Geophysics, pre-print

Manstein AK, Panin GL, Tikunov SY (2008) A device for shallow frequency-domain electromagnetic induction sounding. Russ Geol Geophys 49:430-436

Menghini A, Pagano G, Floris S, Bernini E, Pelorosso M (2010) TDEM method for hydrothermal water detection. First Break 28:93-101

Mitsuhata Y, Imasato T (2009) On-site bias noise correction in multi-frequency Slingram-type electromagnetic induction instruments. J Eng Environ Geophys 14:179-188

Nagler P, Jetton A, Fleming J, Didan K, Glenn E, Erker J, Morino K, Milliken J, Gloss S (2007) Evapotranspiration in a cottonwood (Populus fremontii) restoration plantation estimated by sap flow and remote sensing methods. Agric For Meteorol 144:95-110

Nobes DC (2007) Detecting linear features using the directionality of the HLEM response. In: Proceedings of EAGE Near Surf, 2007, Istanbul

Pankratov OV, Geraskin AI (2010) On processing of controlled source electromagnetic (CSEM) data. Geol Acta 8:31-49

Pardo D, Torres-Verdin C, Demkowicz LF (2007) Feasibility study for 2D frequency-dependent, electromagnetic sensing through casing. Geophysics 72:F111-F118

Pavlov AT, Lepeshkin VP, Pavlova YN (2007) Possibilities and specific features of pulsed inductive electromagnetic sounding of shallow sections under complex geological conditions. Izv Phys Solid Earth 43:251-258

Petho G, Takacs E (2007) Geophysical application of power lines EM fields. In: Proceedings of EAGE Near Surf 2007, Istanbul

Pfaffhuber AA, Monstad S, Rudd J (2009) Airborne electromagnetic hydrocarbon mapping in Mozambique. Explor Geophys 40:237-245

Shen J, Sun W (2008) 2.5-D modeling of cross-hole electromagnetic measurement by finite element method. Petrol Sci 5:126-134

Singleton AC, Osinski GR, Samson C, Williamson MC, Holladay S (2010) Electromagnetic characterization of polar ice-wedge polygons: implications for periglacial studies on Mars and Earth. Planet Space Sci 58:472-481

Slatt RM, Eslinger EV, Van Dyke SK (2009) Acoustic and petrophysical properties of a clastic deepwater depositional system from lithofacies to architectural elements' scales. Geophysics 74:WA35-WA50

Srigutomo W, Kagiyama T, Kanda W, Munekane H, Hashimoto T, Tanaka Y, Utada H, Utsugi M (2008) Resistivity structure of Unzen volcano derived from time domain electromagnetic (TDEM) survey. J Volcanol Geothermal Res 175:231-240

Suzuki K, Oyama T, Kawashima F, Tsukada T, Jyomori A (2010) Monitoring of grout material injected under a reservoir using electrical and electromagnetic surveys. Explor Geophys 41:69-79

Tromp-van Meerveld HJ, McDonnell JJ (2009) Assessment of multi-frequency electromagnetic induction for determining soil moisture patterns at the hillslope scale. J Hydrol 368:56-67

Wirianto M, Mulder WA, Slob EC (2007) A feasibility study of land CSEM reservoir monitoring in a complex 3-D model. Geophys J Int 181:741-755

Utada H, Takahashi Y, Morita Y, Koyama T, Kagiyama T (2007) ACTIVE system for monitoring volcanic activity: a case study of the Izu-Oshima Volcano, Central Japan. J Volcan Geotherm Res 164:217-243 